\title{
Impacts of Storm-Track Variations on Wintertime Extreme Weather Events over the Continental United States
}

\author{
Chen-Geng Ma And Edmund K. M. CHANG \\ School of Marine and Atmospheric Sciences, Stony Brook University, State University of New York, Stony Brook, New York
}

(Manuscript received 28 July 2016, in final form 23 February 2017)

\begin{abstract}
Extratropical cyclones are responsible for many of the high-impact weather events over the United States, including extreme cold, extreme high wind, and extreme heavy precipitation. In this study, impacts from the variations of the cyclone (or storm-track) activity on these extreme events are examined through composites based on map-averaged cyclone activity. Increased cyclone activity enhances the frequency of extreme cold and high wind events over much of the United States, and impacts extreme precipitation around the Ohio River valley. These impacts are largely due to a changing of the tail of the distribution rather than a shifting of the mean. To systematically study these impacts, three singular value decomposition (SVD) analyses have been conducted, each one between the cyclone activity and one kind of extreme event frequency. All three SVD leading modes represent a pattern of overall increase or decrease of storm tracks over the United States. The average of the time series of these leading modes is highly correlated with the observed map-averaged storm track and strongly associated with the Pacific-North America (PNA) pattern and El Niño-Southern Oscillation (ENSO). However, composites based on either the PNA pattern or ENSO do not show as strong impacts as the map-averaged storm track. A second common SVD mode is found that correlates weakly with the North Pacific mode and is likely to be largely due to internal variability. Finally, the potential impacts of projected storm-track change on the frequency of extreme events are examined, indicating that the projected storm-track decrease over North America may give rise to some reduction in the frequency of extreme events.
\end{abstract}

\section{Introduction}

Wintertime extreme weather events that include extreme cold, high wind, and extreme precipitation can cause tremendous loss to human society. Considering their huge impacts, much attention has been paid to study the observed variations of these extremes, the possible forcing and the predicted future change. Midlatitude cyclone activity is a dominant driver for cold season extreme weather events. In the northeastern United States, about $60 \%-80 \%$ of 6-hourly precipitation extremes occur simultaneously with a cyclone at the same grid point, and this percentage value in winter [December-February (DJF)] can be even larger (Pfahl and Wernli 2012). Another study that tries to

Supplemental information related to this paper is available at the Journals Online website: http://dx.doi.org/10.1175/ JCLI-D-16-0560.s1.

Corresponding author e-mail: Edmund K. M. Chang, kar.chang@ stonybrook.edu categorize each precipitation extreme over the United States according to different meteorological causes shows that about $54 \%$ of extremes are near the front of an extratropical cyclone, and $24 \%$ are near the extratropical cyclone low center (Kunkel et al. 2012). Within all of the fatalities associated with high wind over the United States during 1980-2005, 21.4\% of them were caused by nonconvective wind, more than $83 \%$ of which were associated with the passage of midlatitude cyclones (Ashley and Black 2008). Numerous case studies of hazardous weather for the winter over the United States demonstrate that these are mostly related to the passage of deep cyclones (e.g., Bosart 1981; Zhang et al. 2002; Cardone et al. 1996).

Extratropical cyclones develop from the baroclinic energy associated with the large-scale meridional temperature gradient. It is now a general agreement that under a rising greenhouse gas scenario, near-surface temperature will increase (Meehl et al. 2007; Collins et al. 2013). In the Northern Hemisphere (NH), the polar region is projected to experience enhanced warming (Holland and Bitz 2003, Lu and Cai 2009). 
Accelerated warming of the Arctic has already been observed in recent decades (Francis and Vavrus 2012). This polar amplification will lead to weaker equator-topole temperature difference. In the subtropics, static stability is expected to increase, due to the projected maximum warming in the upper troposphere (Frierson 2006). Dynamically, both factors indicate fewer or weaker extratropical cyclones for the future (Bengtsson et al. 2006; Lim and Simmonds 2009). On the other hand, as temperature rises, moisture content in the atmosphere is also expected to increase (Held and Soden 2006). The intensification rate, central pressure minimum, and extreme surface winds and precipitation of cyclones are all expected to increase monotonically with moisture (Booth et al. 2013). Because of these counteracting factors, how cyclone intensity may change in the NH is still rather uncertain (Collins et al. 2013). Models from phase 5 of the Coupled Model Intercomparison Project (CMIP5) have projected a decrease in extratropical cyclone activity in the $\mathrm{NH}$, including North America, for all seasons (Chang et al. 2012; Harvey et al. 2012). Given that extreme weather events are closely related to extratropical cyclone activity, the projected decrease in cyclone activity could have impacts on the frequency of occurrence of these events. But how large will this impact be? Whether it is significant by itself or overwhelmed by other factors that occur simultaneously still needs to be investigated. In this study, we will try to answer these questions systematically and we believe our results may provide a reference for climate model assessment.

During this process, we will explore the relationship between cyclone activity and extreme events to quantify how much the variations in extreme cold, extreme high wind, and extreme precipitation events are related to cyclone activity. Since previous studies have also shown that teleconnections significantly influence both the cyclone activity (Grise et al. 2013; Leathers et al. 1991; Angel and Isard 1998; Kunkel and Angel 1999; Noel and Changnon 1998; Hirsch et al. 2001; Eichler and Higgins 2006) and the weather extremes (Kunkel and Angel 1999; Ning and Bradley 2015; Higgins et al. 2002), we will also examine the relationships among cyclone activity, extreme events, and teleconnections.

\section{Data and methods}

\section{a. Data}

In this study, 6-hourly sea level pressure (SLP) data $\left(2.5^{\circ} \times 2.5^{\circ}\right)$ from the European Centre for MediumRange Weather Forecasts (ECMWF) interim reanalysis (ERA-Interim) are used to quantify the storm track (see below). We have also used the $0.75^{\circ} \times 0.75^{\circ}$ SLP data from ERA-Interim and obtained almost identical results. The dataset is available since 1979.

To study near-surface high wind events, 6-hourly ERA-Interim zonal wind $U$ and meridional wind $V$ $\left(0.75^{\circ} \times 0.75^{\circ}\right)$ data at 850 -hPa level are used. Here we have masked out regions where the surface pressure has been consistently below $850 \mathrm{hPa}$ within the analysis period to make sure that the data are meaningful. We have also examined 925-hPa winds and obtained very similar results. Here $850-\mathrm{hPa}$ winds are used instead of $10-\mathrm{m}$ winds since they represent the wind field above the surface boundary layer and are a more robust quantity (less dependent on the model boundary layer parameterizations; see Bengtsson et al. 2009). The mean flow at each point is derived from the vector sum of winter mean $\bar{U}$ and $\bar{V}$. For high wind events, the wind speed (as the vector sum of $U$ and $V$ ) is calculated every $6 \mathrm{~h}$. The goal of this study is to explore the large-scale relationship between cyclone activity and multiple kinds of extreme events. Given that station surface wind observations are spatially and temporally inhomogeneous, we believe that a first analysis making use of gridded data is appropriate. Previous studies (e.g., Karremann et al. 2014) have also used analyzed winds to examine extreme wind events. Nevertheless, sensitivity studies using station observations to verify the findings based on gridded data should be conducted in the future.

To show the relationship between the storm track and the mean-state temperature and extreme cold events, daily minimum temperature gridded station data $\left(2.5^{\circ} \times 3.75^{\circ}\right)$ from HadGHCND (Caesar et al. 2006) are used. These data are created by the Hadley Centre for Climate Prediction and Research, using the Global Historical Climatology Network-Daily (GHCND) database developed by the National Climatic Data Center as its observations. The data are available only on land, between 1946 and 2010.

For extreme precipitation, the Climate Prediction Center (CPC) unified gauge-based daily precipitation analysis over the continental United States (Xie et al. 2007; Chen et al. 2008) is used. This dataset has a resolution of $0.25^{\circ} \times 0.25^{\circ}$ and is available only within the continental United States since 1948.

Since the ERA-Interim data start at 1979, and the HadGHCND data end in 2010, our study's primary period is from 1979 to 2010 . For the analyses that need strictly the same grid (e.g., point-to-point correlation or regression), bilinear interpolation is used for wind, temperature, and storm track, and area-conserved interpolation (Jones 1999) is used for precipitation, transforming the finer grid size data onto the coarser grid size. 
To understand how the patterns and composites we found are related to larger-scale factors, we examined geopotential height by using the monthly ERA-Interim 500 -hPa geopotential field $\left(2.5^{\circ} \times 2.5^{\circ}\right)$ and SST $\left(1^{\circ} \times 1^{\circ}\right)$ provided by the Hadley Centre Sea Ice and Sea Surface Temperature dataset (HadISST) (Rayner et al. 2003). We also examined the Niño-3.4 index (east central tropical Pacific SST; $\left.5^{\circ} \mathrm{N}-5^{\circ} \mathrm{S}, 170^{\circ}-120^{\circ} \mathrm{W}\right)$ and the Pacific-North American (PNA) pattern index (PNA index) provided by the NOAA Climate Prediction Center. These monthly indices are averaged to form the winter mean. According to the $\mathrm{CPC},{ }^{1}$ the procedure used to calculate the PNA index is based on rotated principal component analysis (RPCA) (Barnston and Livezey 1987) applied to monthly standardized 500-hPa height anomalies obtained from the Climate Data Assimilation System in the analysis region $20^{\circ}-90^{\circ} \mathrm{N}$, with the standardization based on data from 1950 to 2000 .

To estimate the potential impacts of projected stormtrack change on extreme events in the future, 6-hourly SLP data for both the historical and future periods from 28 CMIP5 models are used to derive the storm-track change. The list of models is shown in Table S1 of the supplemental material. This dataset is available for 1950-2005 from the historical simulations and 2006-98 for future projections. We consider the experiments under the high emission representative concentration pathway (RCP) 8.5 scenario, in which the greenhouse gas forcing is about $8.5 \mathrm{~W} \mathrm{~m}^{-2}$ at the end of the twentyfirst century.

\section{b. Methods}

There are two families of methods that are widely used to study cyclone activity. The first directly studies cyclone trajectories using objective tracking algorithms (Hodges 1999; Hoskins and Hodges 2002). Previous studies suggest that the results are usually robust for strong cyclones but sensitive for weaker ones (Neu et al. 2013; Raible et al. 2008). On the other hand, passages of cyclones close to any location generate rapid pressure perturbations, circulation anomalies, and temperature advection. Thus the use of temporal variance or covariance of meteorological variables is an alternative way to capture cyclone activity. A considerable amount of work has been done to explore this possibility since the 1970s. By mapping the root-mean-square and covariance statistics as well as one-point teleconnection patterns based on time-filtered data that retain periods within the 2.5-6-day band, these previous studies

\footnotetext{
${ }^{1}$ See http://www.cpc.ncep.noaa.gov/products/precip/CWlink/pna/ pna.shtml.
}

(Blackmon et al. 1977, 1984a,b and Lau 1978) reported that the most active disturbances tend to travel eastward through propagation within two elongated zones spanning the North Pacific and the North Atlantic. These maximum temporal variability regions are characterized by vigorous transport of heat and vorticity by highfrequency eddies and their centers coincide with the "storm track" region, introduced by earlier surveys of cyclone trajectories of individual cyclone centers (e.g., Petterssen 1956, 267-276).

Since the first method still has robustness issues and its results are usually noisier and harder to interpret, and the temporal variance method has been shown to be a good approximation that captures the essence of midlatitude cyclone activity, in this study we will focus on the second method. One should keep in mind that by using the filtered variance metrics to measure the stormtrack activity, the variance related to anticyclones is also included. However, anticyclones are usually slow moving and have pressure anomalies that are weaker than those of cyclones (Hoskins and Hodges 2002), so the variance is likely to be dominated by cyclones. We have examined climatological maps of cyclone frequency (not shown) and found them to closely resemble those for variance statistics. In future studies we will directly link cyclone-track statistics to extreme events.

Here, we use the 24-h difference filtered variance of SLP to measure extratropical cyclone activity (ECA) called ECApp (Wallace et al. 1988:

$$
\operatorname{ECApp}=\overline{[\operatorname{SLP}(t+24 \mathrm{~h})-\operatorname{SLP}(t)]^{2}},
$$

where the variance is taken usually over a month or a season. Similar metrics are widely used in previous studies to quantify cyclone or "storm track" activity (Lau 1988; Feser et al. 2015; Alexander et al. 2005; Chang et al. 2012, 2016, etc.).

To see the effects the storm track has on other variables, we define the high- and low-storm-track composite by averaging ECApp over our domain (the continental part within $25^{\circ}-55^{\circ} \mathrm{N}, 60^{\circ}-140^{\circ} \mathrm{W}$, which is the land area within the black rectangle in Fig. 1b) and select the highest (lowest) 10 winters as the high (low) composite (Fig. 1a). For extreme events, there could be several different ways to define its threshold: for example, the threshold could be a constant, or a certain percentile over all records in each station, etc. Since percentile-based events are widely used within climate studies (Sen Roy and Balling 2004; Abatan et al. 2016, etc.), here we take our threshold as the local top (or bottom) first (or 5th) percentile over the whole period (DJF 1979-2010). A local threshold is reasonable, given that building codes are often based on local climatological conditions 

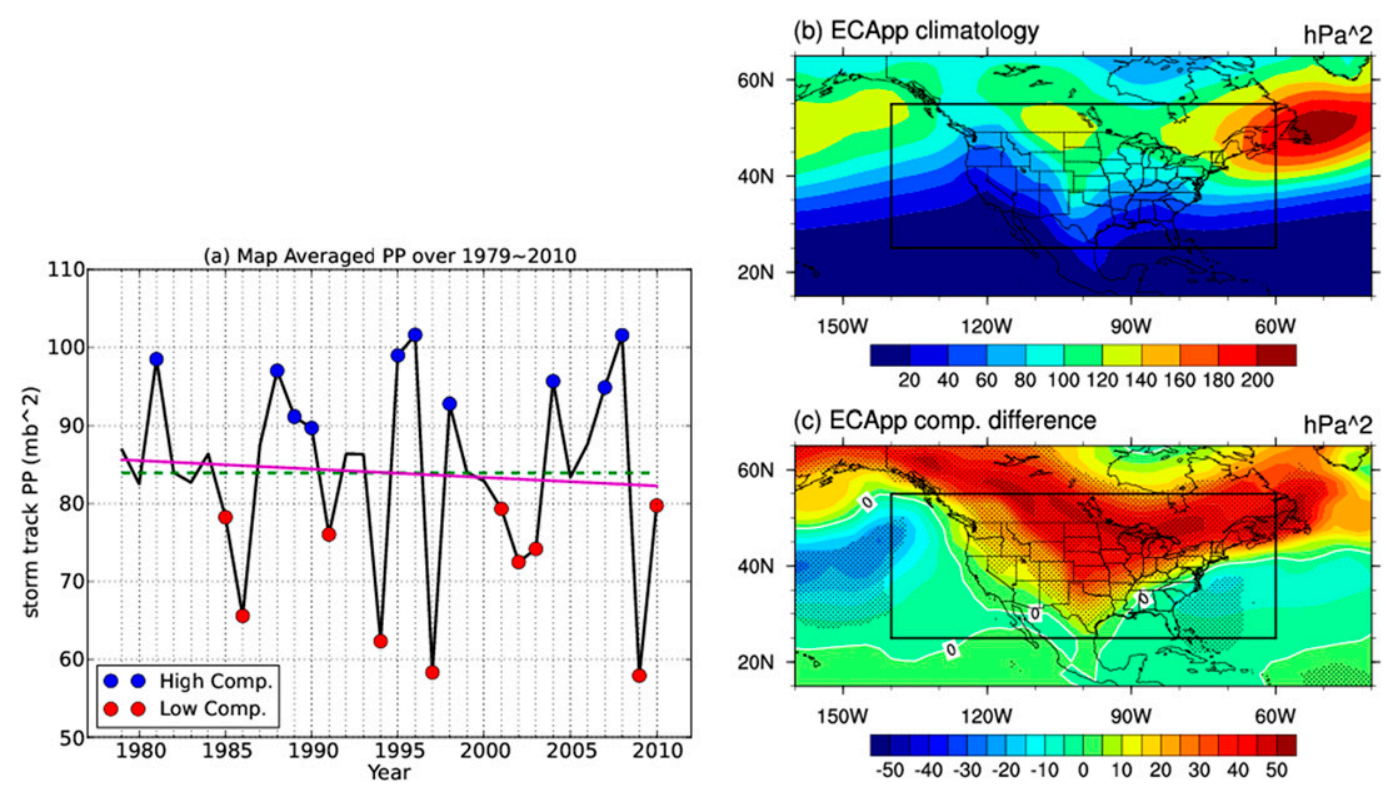

FIG. 1. (a) Map-averaged (continental part within $25^{\circ}-55^{\circ} \mathrm{N}, 60^{\circ}-140^{\circ} \mathrm{W}$ ) ECApp for each winter, where the 10 high (low) ECApp years are represented by blue (red) dots, the green dashed line represents the mean ECApp value during the entire period (DJF 1979-2010), and the purple line represents the linear fitted ECApp. (b) Climatology of ECApp during DJF 1979-2010. (c) Difference in ECApp between 10 high-ECApp and 10 lowECApp years. The dotted regions in (c) are significant at the 5\% level based on the Student's $t$ test.

(e.g., Klawa and Ulbrich 2003; Karremann et al. 2014). The percentage of time the threshold is exceeded is called the 99th (95th) percentile events frequency. Since we use a local percentile as threshold, this measure is well defined most of time. In the rare cases that the threshold is not meaningful (e.g., in very dry regions where the top 5 th percentile of precipitation might be zero), we simply mask that point to be missing. For grid points that contain missing data, if the missing part is less than $10 \%$ of its length, the nonmissing part is used, otherwise the point is not included in the analysis.

To test the robustness of the results based on using the map-averaged ECApp as the separator to form composites, we performed a singular value decomposition (SVD; Bretherton et al. 1992) between ECApp and the 99th percentile frequency of each kind of events separately. SVD, also known as maximum covariance analysis, is a method that can efficiently find pairs of patterns that exhibit maximum covariance between two fields. More details about the method can be found in the supplemental material. Before an SVD is performed, the data are weighted by the square root of cosine latitude to take into account the area each grid box represents. To see how much the three kinds of extreme events are related to the storm track, we show our patterns through the homogeneous correlation map of ECApp and heterogeneous correlation map of extreme events frequency-in other words, correlations of the
ECApp and extreme frequency fields based on the ECApp time series for the SVD pair. The ECApp time series from the three SVDs are compared to find interesting common modes of variations.

After comparing the modes from the three SVDs, some common modes are found to share similar patterns and time series. An average of the ECApp time series of these three SVD modes within a common mode is taken. The time series are then used to form composites to further explore these modes. Correlations with largerscale variations (SST, geopotential height) are also examined to explore whether these modes are related to known teleconnections (e.g., PNA or ENSO).

To see how these SVD modes relate to the modes of variability of the storm track and these extremes, we have performed empirical orthogonal function (EOF) analyses on the storm track (ECApp) and the extreme frequency fields. These will be discussed in the supplemental material.

\section{Results}

\section{a. Composites based on ECApp time series}

As stated in section 2b, ECApp is averaged over the domain and the highest and lowest 10 winters are selected to form the high and low composite. Note that this simple map average is nearly identical to the leading EOF of 
(a) High ECApp yrs

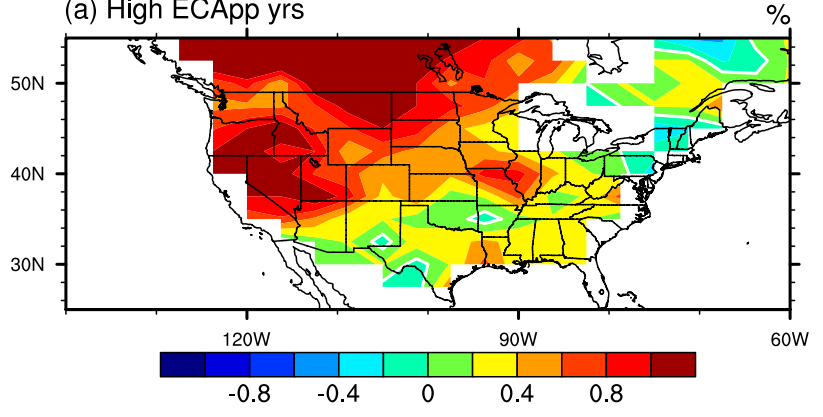

(c) $99 \%$ - Tmin frequency difference

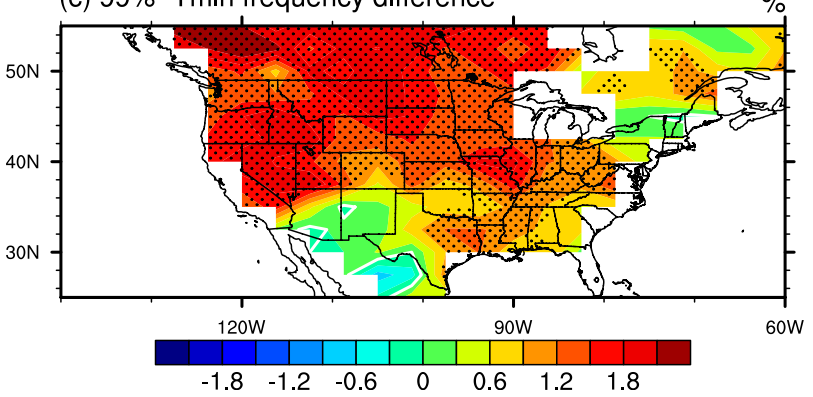

(b) Low ECApp yrs

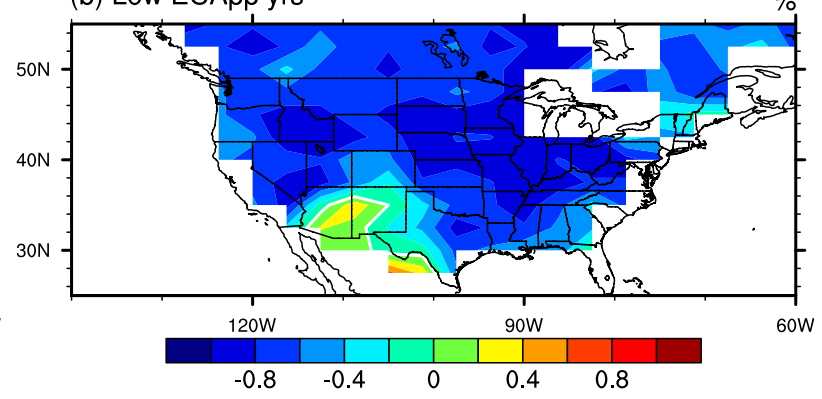

(d) threshold Tmin

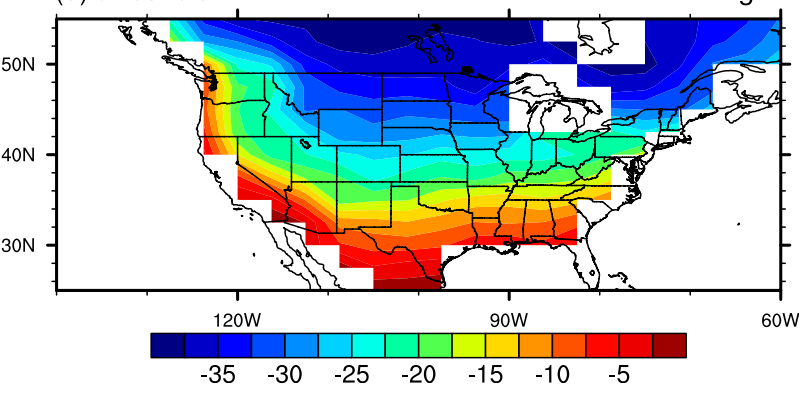

FIG. 2. Relative frequency of 99th percentile extreme cold events (based on HadGHCND daily minimum temperature data) minus $1 \%$ within (a) 10 high-ECApp years and (b) 10 low-ECApp years, where the white contour is the zero contour, but physically represents $1 \%$. (c) Difference between (a) and (b), where the dotted regions represent differences that are significant at the 5\% level, and the white contour is the zero line. (d) The local top first-percentile cold minimum temperature $\left({ }^{\circ} \mathrm{C}\right)$ during the entire period (DJF 1979-2010).

ECApp variability over North America with the correlation coefficient between them as high as -0.986 (see the supplemental material and Fig. S5 therein). The years selected for each composite can be seen in Fig. 1a. Within our time range (DJF 1979-2010), the trend in ECApp is slightly negative at $-0.108 \mathrm{hPa}^{2} \mathrm{yr}^{-1}$, but this trend is not statistically significant. Figure $1 \mathrm{~b}$ shows the climatology of ECApp. The largest value is about $200 \mathrm{hPa}^{2}$ at the entrance of the Atlantic storm-track region. The difference in ECApp between high and low storm-track years is shown in Fig. 1c. Dotted regions correspond to differences that are at the 5\% significance level based on the Student's $t$ test. Figures $1 \mathrm{~b}$ and $1 \mathrm{c}$ together provide an impression of how much the storm-track activity differs between the high and low storm-track years.

To show the impact of storm-track variations on extreme cold events, the deviation of the frequency at which the local 99th percentile extreme cold threshold is exceeded beyond $1 \%$, during the high composite years (Fig. 2a) and the low composite years (Fig. 2b), is computed for each grid box. The threshold, the local top first-percentile cold minimum temperature, is shown in Fig. 2d, with the coldest value below $-35^{\circ} \mathrm{C}$ in southern Canada, and the warmest value above $-5^{\circ} \mathrm{C}$ in Texas and Mexico. The probability of a first-percentile event happening is $1 \%$ (or a deviation of zero). Given this fact, values over $1 \%$ in the northwestern United States and southwestern Canada during the high composite years, and values close to $-0.8 \%$ over much of the continental United States during the low composite years, are highly anomalous. Finally, the difference between the high and low storm-track years is shown in Fig. 2c. The difference at most grid boxes is significant at the $5 \%$ level, with extended regions having a difference value of over $1 \%$, even approaching $2 \%$ at some locations.

The impacts of storm-track variations on high wind and extreme precipitation events are displayed using the same format. Figures $3 \mathrm{a}$ and $3 \mathrm{~b}$ show the deviation of the 99th percentile high wind frequency from $1 \%$ at $850 \mathrm{hPa}$ for high and low storm-track years, and it is apparent that the patterns are almost exactly opposite. Figure $3 \mathrm{c}$ shows the difference between Figs. 3a and 3b, and Fig. 3d shows the threshold (the local top first-percentile high wind speed). The maximal region in Fig. $3 \mathrm{c}$ is located in the eastern part of the United States to the south of the Great Lakes (the Ohio River valley), with values generally above $0.9 \%$, and peaking around $1.5 \%$. Wind speed over the Rocky Mountain regions might also be large; however, the surface pressure there usually drops below $850 \mathrm{hPa}$. Hence we have masked out these regions.

For extreme precipitation, during the high storm-track years (Fig. 4a) there are more extreme events south of the Great Lakes and over the northwestern United States (from $0.4 \%$ to $1.2 \%$ ) but fewer over Texas, Nebraska, 
(a) High ECApp yrs

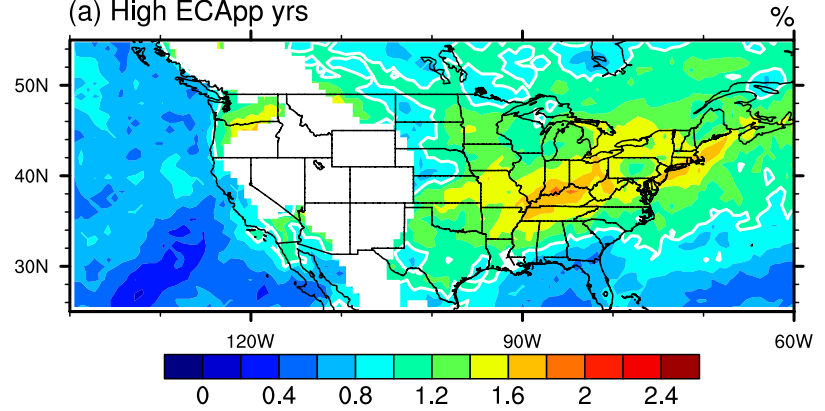

(c) $99 \%$ - high wind frequency difference

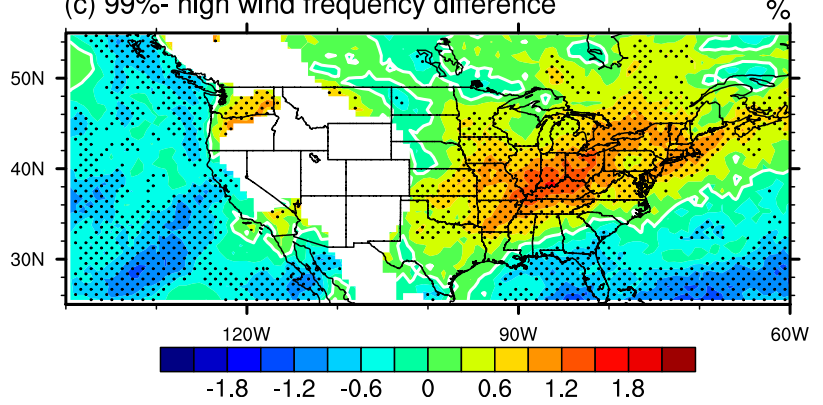

(b) Low ECApp yrs

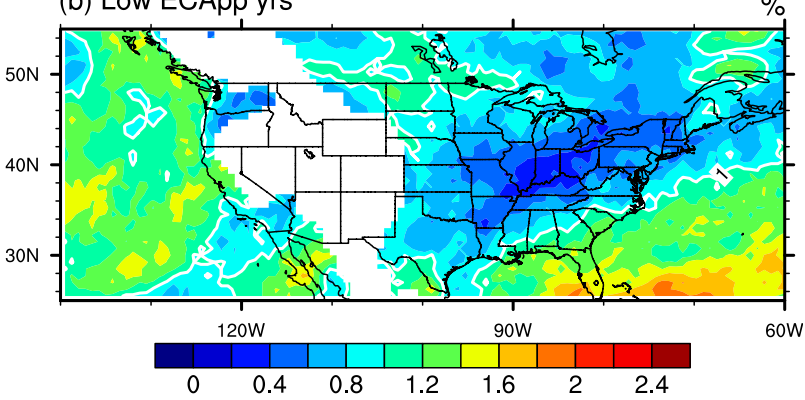

(d) threshold $850 \mathrm{mb}$ Wind Speed

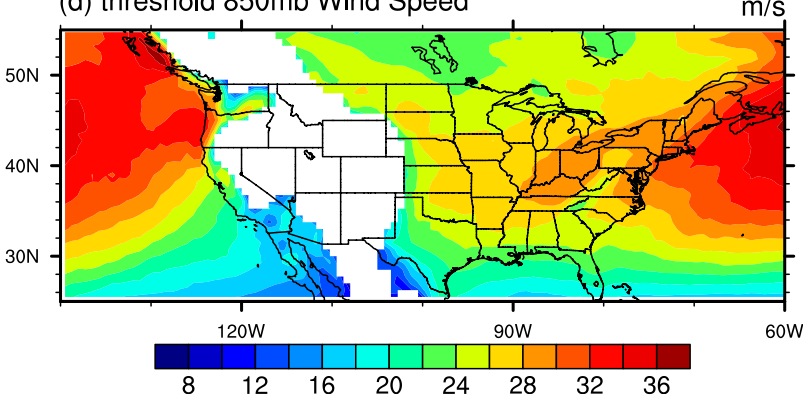

FIG. 3. As in Fig. 2, but for high wind events. The region where the surface pressure has consistently been below $850 \mathrm{hPa}$ has been masked out. The unit in (d) is $\mathrm{m} \mathrm{s}^{-1}$.

Southern California, and along the U.S. East Coast (from $-0.6 \%$ to $-0.2 \%$ ). During the low storm-track years (Fig. 4b), almost the opposite happens. Figure 4c shows the difference in frequency of 99th percentile heavy precipitation events between the high and low storm-track years. Given that the precipitation data are high resolution $\left(0.25^{\circ} \times 0.25^{\circ}\right)$, the results are rather noisy. Areas with significant difference (shown as the meshed regions) lie mostly south of the Great Lakes, with only scattered regions over the Pacific Northwest and Texas. The value (a) High ECApp yrs

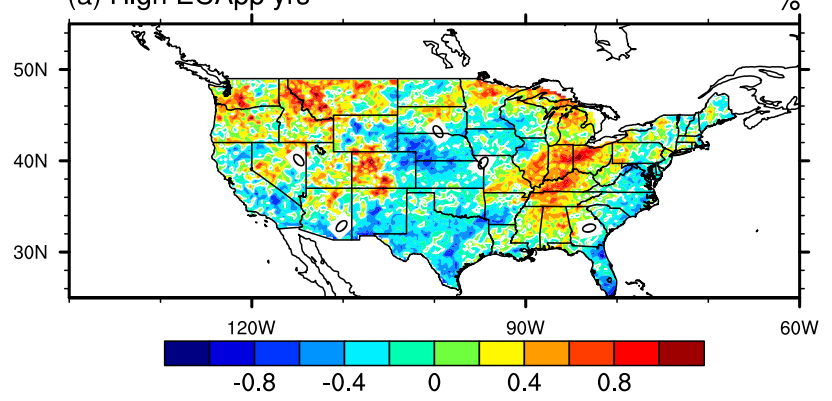

(c) High ECApp yrs - Low ECApp yrs

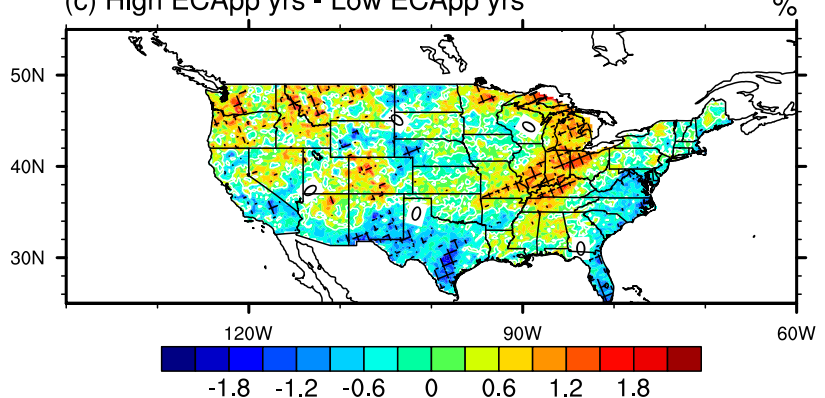

(b) Low ECApp yrs

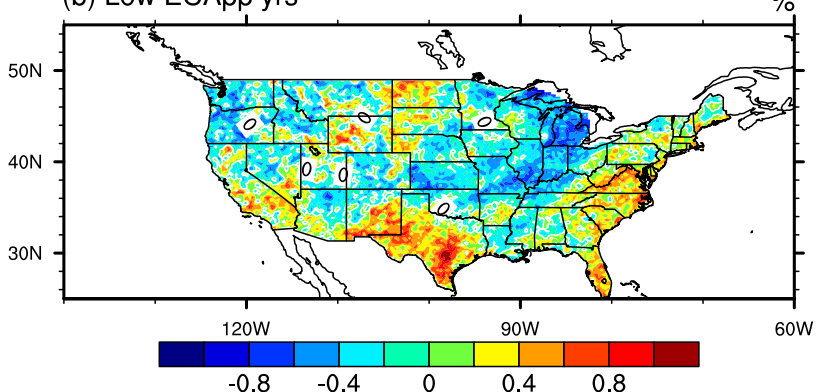

(d) threshold Precipitation

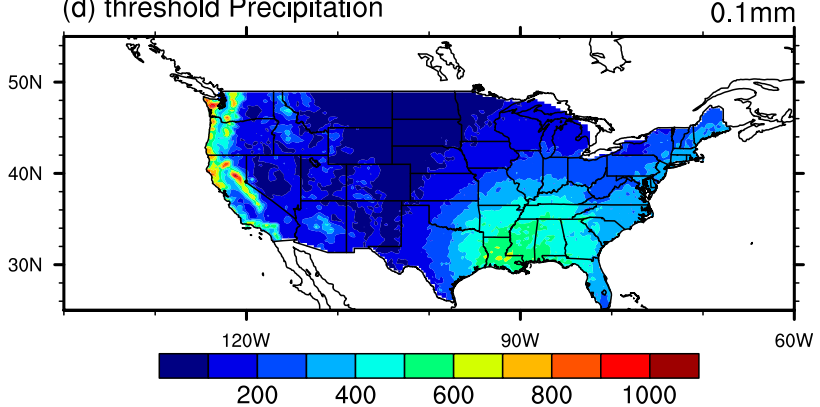

FIG. 4. As in Fig. 2, but for heavy precipitation events. The unit in (d) is $0.1 \mathrm{~mm} \mathrm{day}^{-1}$. 
(a) Mean Tmin difference

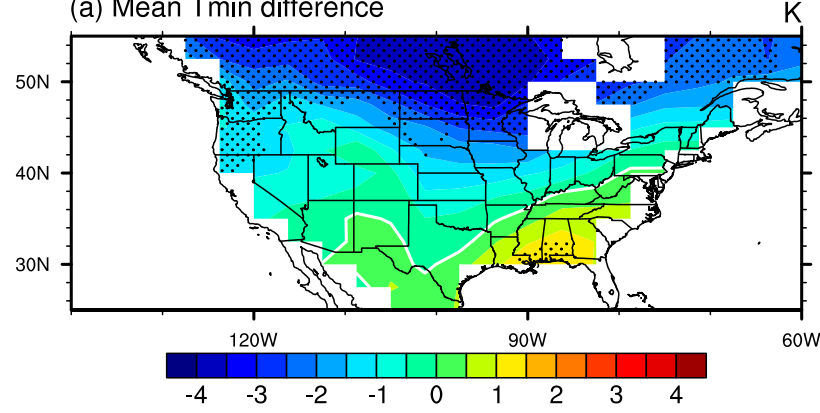

(c) Mean $850 \mathrm{mb}$ Wind Speed difference

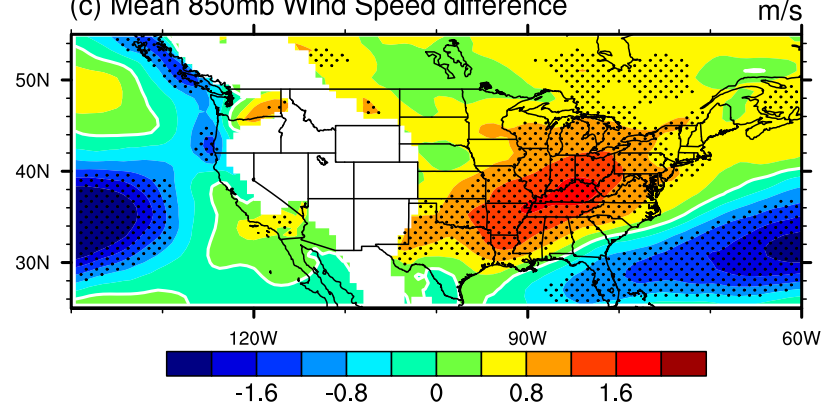

(e) Mean ECApp difference

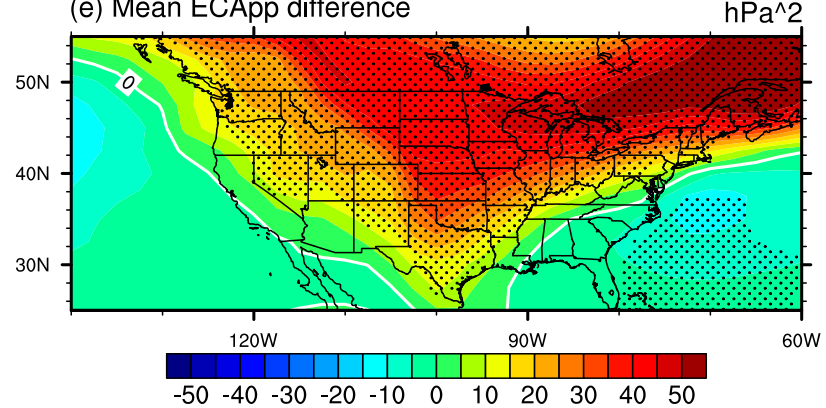

(b) $99 \%-T m i n$ frequency difference

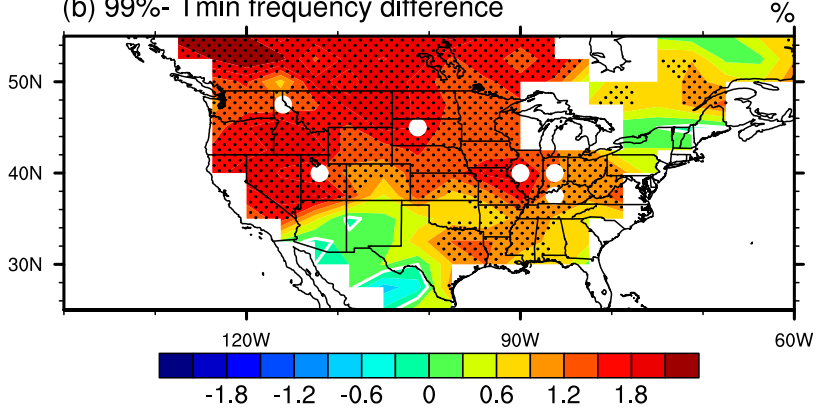

(d) $99 \%$ - high wind frequency difference

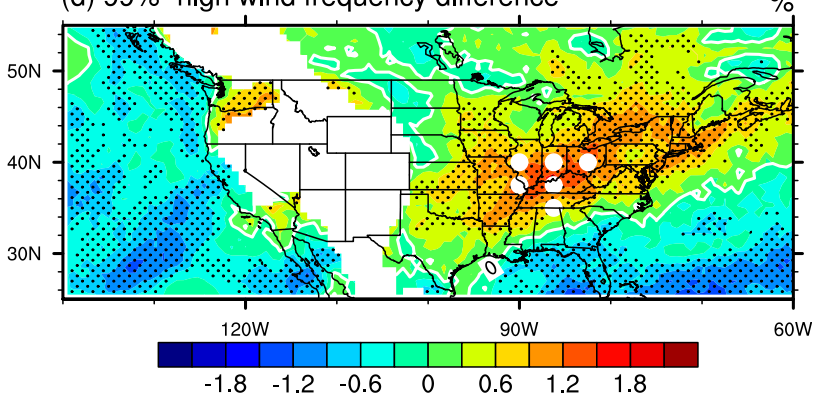

(f) $99 \%$ - Precip. frequency difference

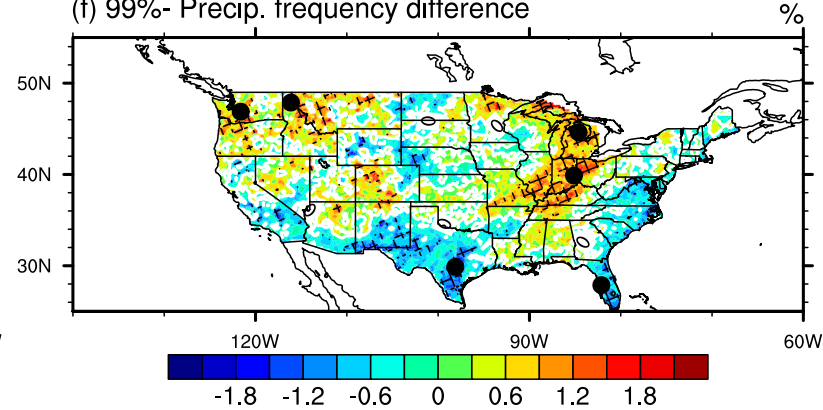

FIG. 5. Composite difference between 10 high-ECApp winters and 10 low-ECApp winters for (a) mean minimum temperature $\left({ }^{\circ} \mathrm{C}\right)$, (b) 99th percentile extreme cold events frequency (same as Fig. 2c), (c) mean flow speed ( $\mathrm{m} \mathrm{s}^{-1}$ ); (d) 99th percentile extreme high wind frequency (same as Fig. 3c), (e) mean ECApp difference (hPa ${ }^{2}$; same as Fig. 1c), and (f) 99th percentile extreme precipitation frequency (same as Fig. 4c). The dotted regions in (a)-(e) and the regions covered by the meshed pattern in (f) show the regions that are significant at the $5 \%$ level. Since the largest and smallest $10 \mathrm{yr}$ of the first common mode time series are the same as the 10 high- and low-ECApp years, this figure also represents the composite difference of the first common mode. The region where the surface pressure has consistently been below $850 \mathrm{hPa}$ has been masked out in (c) and (d).

of the difference around the Great Lakes and the northwestern United States reaches about $0.8 \%$, and the values in Texas and the East Coast also reach about $-0.8 \%$.

To show the robustness of these results, the difference in the frequency of 95th percentile extreme events are shown in Fig. S1 of the supplemental material. The value of the difference is up to $5 \%$ within the maximum regions for extreme cold and high wind events. For extreme precipitation, the value is up to $3 \%$ or $4 \%$ in maxima and $-4 \%$ or $-5 \%$ in minima, but the significant area becomes much larger than for the 99th percentile.

Our results indicate significant differences in the frequency of extreme events during the high and low stormtrack winters. However, it is also true that high stormtrack winters are usually colder and have higher mean wind speed. Figures $5 \mathrm{a}$ and $5 \mathrm{c}$ show the composite mean difference (high composite minus low composite) of mean minimum temperature and mean flow speed, respectively. To facilitate direct comparisons with the difference in the frequency of extreme events, the difference in the frequency of extreme cold (Fig. 2c) and high wind (Fig. 3c) events are reproduced in Figs. 5b and 5d. Figure 5a shows that during high storm-track years, it is significantly colder over southern Canada and the northern United States, while temperature changes are minimal over the subtropics. This increase in the thermal gradient is consistent with the increase in storm-track activity, since cyclones derive their energy from the equator-to-pole temperature gradient. The enhanced thermal gradient also leads to increase in 
thermal wind south of this cold anomaly, consistent with increase in mean wind over eastern United States (Fig. 5c). Colder mean temperature and higher mean wind may result in higher frequency of extreme cold and high wind events. While changes in mean flow and storm tracks are symbiotic in nature (e.g., Cai and Mak 1990), part of the mean flow change could be externally forced (e.g., by ENSO; see discussion in next section), so it is important to clarify whether the changes in the frequency of extreme events are mostly due to shifts in the means or changes in the tails of the distribution. In summary, it is possible that the shifting of the mean state is the only factor that leads to the significant impacts on extreme events, and the storm-track variation is just a result of mean-state change and has minor contributions to changes in the extreme events. Alternatively, there is another possibility that, even though the storm-track variations are influenced by the mean state shifting, the storm track itself is still a significant factor that impacts the extreme events, and both the mean-state and stormtrack variations are important to the extreme events.

To show that the storm track is a significant factor that leads to the impacts shown in Figs. 2-4, we have examined histograms showing the frequency distribution of the occurrence of minimum temperature for multiple grid boxes. Figure 6 shows the histogram of minimum temperature (Tmin), where the solid (meshed) bars represent the high (low) composite. These single points (locations indicated in Fig. 5b) are selected either from the maximum regions in Fig. $2 \mathrm{c}$ or from a region that shows a strong maximum during high composite years in Fig. 2a or strong minimum during low composite years in Fig. $2 \mathrm{~b}$. The composite mean difference of the mean minimum temperature and mean flow speed can be seen in Tables 1 and 2. Within Figs. 6a-f, the composite mean difference is smaller than one bin size $(2.5 \mathrm{~K})$. We can see that toward the cold end of each panel, there are two or three bins in which only the high composite has counts, while the low composite is almost empty. The two facts together imply that even if we shift the two composites onto the same mean value, the high composite still has many more extreme cold events than the low composite. To confirm this statement, we have shifted the two histograms onto the same mean value by removing the mean from each composite, and a zoom-in of the cold tails are shown in Fig. S2 of the supplemental material, which clearly shows that the high composites have longer tails even if the means are removed. Hence the high storm-track winters have significantly more extreme cold events, not just because the mean temperature is lower but also because the strong cyclone activity has changed the probability distribution of minimum temperature by providing it with a longer tail.
Similar results are found for extreme high wind events. Figure 7 shows the histograms of $850-\mathrm{hPa}$ wind speed for high and low composites at six points. These points (see Fig. 5d and Table 2) are all picked in the region surrounding and south of the Great Lakes, where both the composite difference of mean flow and the extreme high wind frequency show their maximum. At the high wind speed end of Figs. 7a-f, there are two to three bins where only the high composite has counts. The composite mean differences (shown in Table 2) are also lower than one bin size $\left(2 \mathrm{~m} \mathrm{~s}^{-1}\right)$. The high wind speed end of the histograms shifted to zero mean is shown in Fig. S3 of the supplemental material. We can see that generally the high composites still have more extreme events even when the shift in the mean is taken out.

In Fig. 8, the histograms of precipitation amounts for high and low composites at six locations (see Table 3) are shown. We have selected four (two) points where Fig. 5 shows more extreme precipitation in high (low) composite. Again, at all these locations, the composite mean differences (Table 3) are all smaller than one bin size, while the histograms show that more extreme events are found in a number of the most extreme bins for the composites that have higher frequency. In Fig. S4 of the supplemental material, the tails of the composite histograms with the means removed are shown. These again confirm that shift in the mean cannot account for all the differences in the frequency of extreme precipitation events.

\section{b. SVD analysis of ECApp and extreme frequencies}

Up to now, we have examined the relationship between storm-track and extreme event statistics using composites based on storm-track activity spatially averaged over the entire continental United States. It is likely that there are other modes of variability that are more regional in nature. To examine this, we have performed three SVDs separately, each one between the ECApp and the frequency of one kind of extreme events, whose threshold is the local 99th percentile. Since we want to know how extreme event statistics are affected by storm-track variations, we show our results as the homogeneous correlation pattern of ECApp and the heterogeneous correlation pattern of the frequency of extreme events. Figure 9 shows the first SVD mode between ECApp and extreme cold frequency (Figs. 9a,b), the first SVD mode between ECApp and extreme wind frequency (Figs. 9c,d), and the first SVD mode between ECApp and extreme precipitation frequency (Figs. 9e,f). It is clear that the three homogeneous correlation patterns of ECApp (Figs. 9a,c,e) look similar to each other, showing an overall increase of ECApp over much of 
(a) Indiana, High(solid) \& Low(mesh) composite

(b) Idaho, High(solid) \& Low(mesh) composite

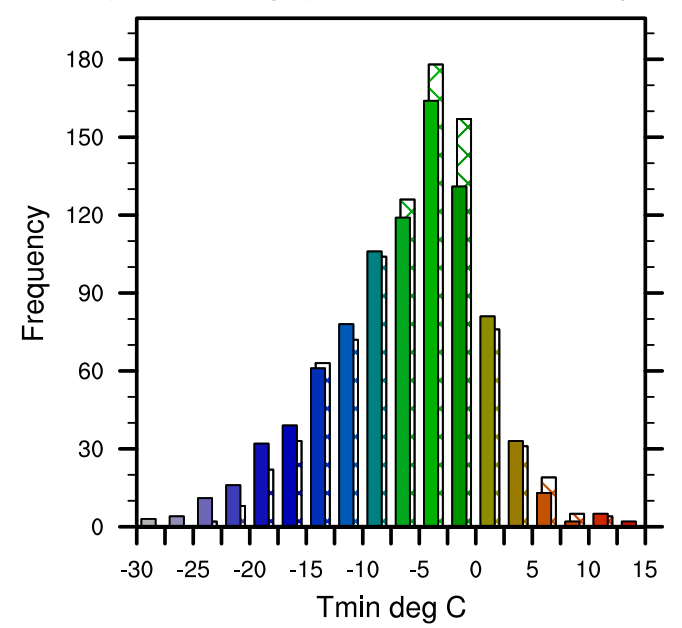

(c) Illinois, High(solid) \& Low(mesh) composite

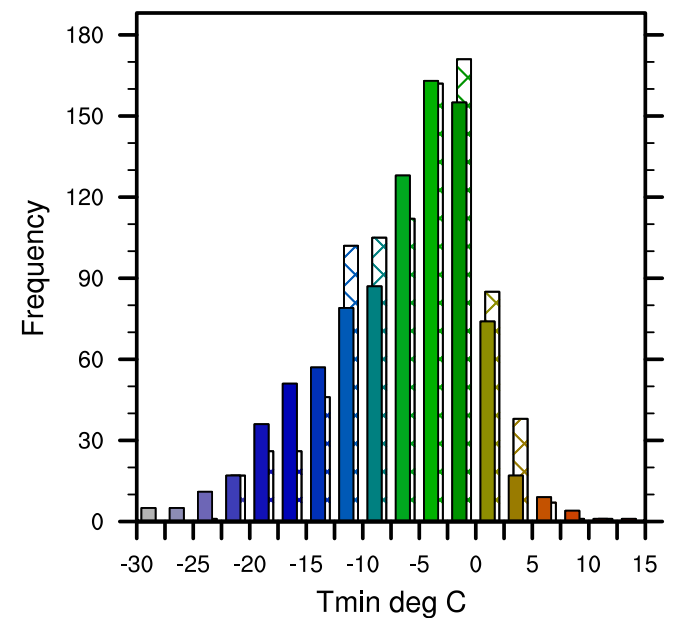

(e) Kentucky, High(solid) \& Low(mesh) composite

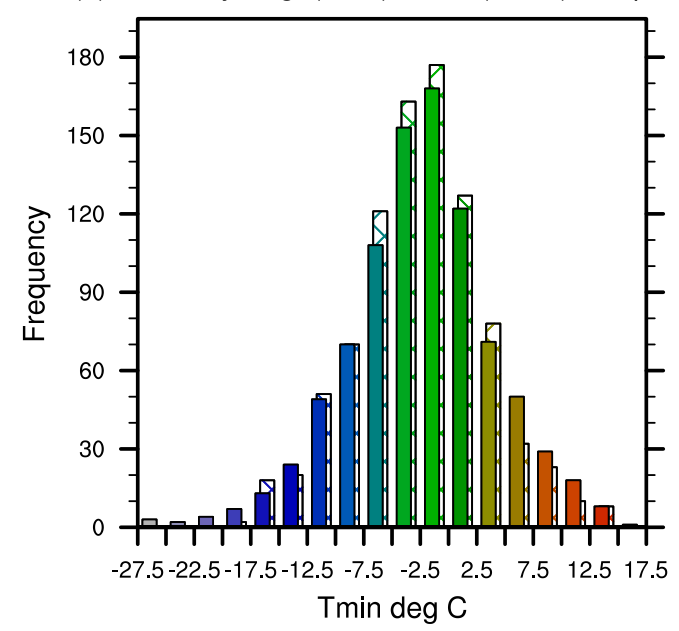

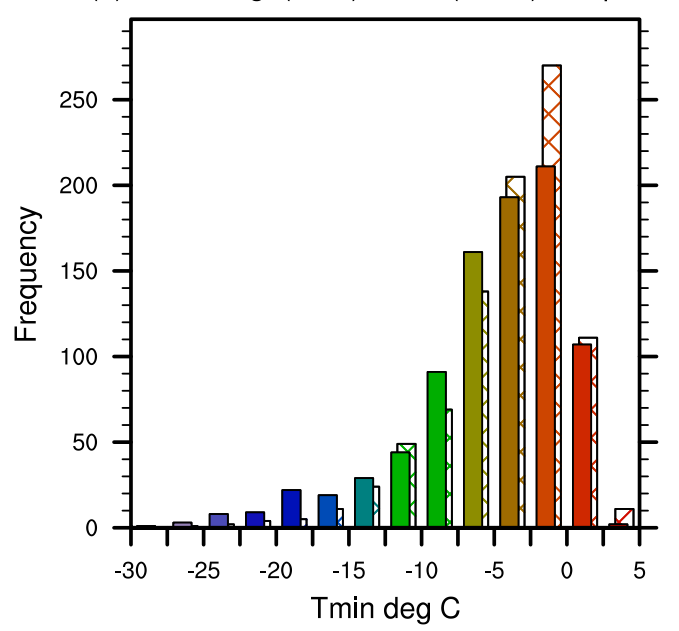

(d) Dakota, High(solid) \& Low(mesh) composite

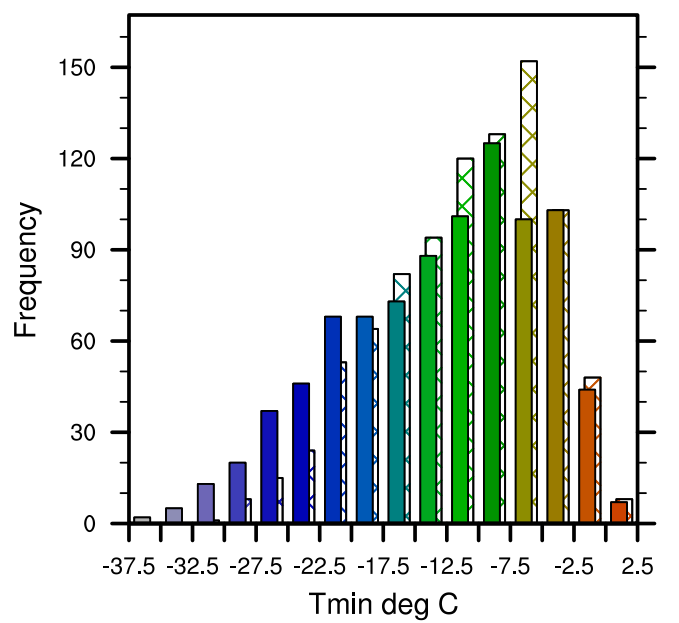

(f) Utah, High(solid) \& Low(mesh) composite

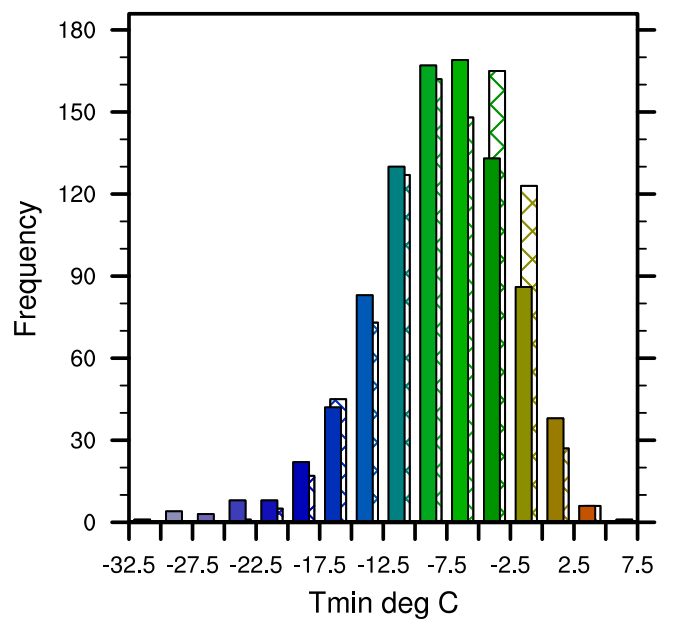

FIG. 6. Histograms of occurrence of minimum temperature for high-ECApp years (solid bar) and low-ECApp years (meshed non-solid bar) in (a) Indiana $\left(40^{\circ} \mathrm{N}, 86.25^{\circ} \mathrm{W}\right)$, (b) Idaho $\left(47.5^{\circ} \mathrm{N}, 116.25^{\circ} \mathrm{W}\right)$, (c) Illinois $\left(40^{\circ} \mathrm{N}\right.$, $\left.90^{\circ} \mathrm{W}\right)$, (d) South Dakota $\left(45^{\circ} \mathrm{N}, 101.25^{\circ} \mathrm{W}\right)$, (e) Kentucky $\left(37.5^{\circ} \mathrm{N}, 86.25^{\circ} \mathrm{W}\right)$, and (f) Utah $\left(40^{\circ} \mathrm{N}, 112.5^{\circ} \mathrm{W}\right)$. Note that for daily minimum temperature, the bottom $1 \%$ for the whole $32-\mathrm{yr}$ period corresponds to 28 events, within which the contributions of high and low composite are shown in Table 1. 
TABLE 1. Locations and composite minimum temperatures for histograms shown in Fig. 6 and Fig S2. The extreme counts show the counts of events within one composite that exceeds the local 99th percentile threshold of cold minimum temperature.

\begin{tabular}{|c|c|c|c|c|c|c|}
\hline \multirow[b]{2}{*}{$\begin{array}{l}\text { Locations selected for minimum } \\
\text { temperature on surface }\end{array}$} & \multicolumn{2}{|c|}{ High composite } & \multicolumn{2}{|c|}{ Low composite } & \multicolumn{2}{|c|}{ Composite difference } \\
\hline & $\begin{array}{l}\text { Mean Tmin } \\
\left({ }^{\circ} \mathrm{C}\right)\end{array}$ & Extreme counts & $\begin{array}{l}\text { Mean Tmin } \\
\left({ }^{\circ} \mathrm{C}\right)\end{array}$ & Extreme counts & $\begin{array}{l}\text { Mean Tmin } \\
\left({ }^{\circ} \mathrm{C}\right)\end{array}$ & Extreme counts \\
\hline Indiana $\left(40^{\circ} \mathrm{N}, 86.25^{\circ} \mathrm{W}\right)$ & -6.49 & 13 & -5.60 & 2 & -0.89 & 11 \\
\hline Idaho $\left(47.5^{\circ} \mathrm{N}, 116.25^{\circ} \mathrm{W}\right)$ & -5.34 & 14 & -4.17 & 3 & -1.17 & 11 \\
\hline Illinois $\left(40^{\circ} \mathrm{N}, 90^{\circ} \mathrm{W}\right)$ & -6.86 & 17 & -5.81 & 0 & -1.05 & 17 \\
\hline South Dakota $\left(45^{\circ} \mathrm{N}, 101.25^{\circ} \mathrm{W}\right)$ & -13.07 & 17 & -11.15 & 1 & -1.92 & 16 \\
\hline Kentucky $\left(37.5^{\circ} \mathrm{N}, 86.25^{\circ} \mathrm{W}\right)$ & -2.48 & 10 & -2.66 & 1 & 0.18 & 9 \\
\hline $\operatorname{Utah}\left(40^{\circ} \mathrm{N}, 112.5^{\circ} \mathrm{W}\right)$ & -8.24 & 16 & -7.48 & 2 & -0.76 & 14 \\
\hline
\end{tabular}

the continental United States, which is coincidently very similar to the pattern obtained based on area-averaged ECApp discussed above (Fig. 1c), whose time series have correlation coefficients that are as high as $0.97,0.98$, and 0.99 with each of the corresponding ECApp time series of the three leading SVD modes. Meanwhile, the three heterogeneous correlation patterns of extreme events (Figs. 9b,d,f) also bear a lot of similarities to the composite differences in extreme event frequency (Figs. 2c, $3 \mathrm{c}$, and $4 \mathrm{c}$ ). The first SVD mode between ECApp and extreme cold explains $62.7 \%$ of the squared covariance fraction (SCF) and accounts for $35.5 \%$ of the variance of ECApp and $31.4 \%$ of the variance of the top firstpercentile cold events frequency. The first SVD mode between ECApp and extreme high wind explains $77.8 \%$ of the SCF, $44.3 \%$ of the variance of ECApp, and $22.4 \%$ of the variance of the top first-percentile high wind frequency. Finally, the first SVD mode between ECApp and extreme precipitation explains $56.9 \%$ of the SCF, $43.6 \%$ of the variance of ECApp, and $6.8 \%$ of the variance of top first-percentile precipitation frequency. All these three leading modes occupy a dominant part of SCF between ECApp and extreme frequency, and they also explain a large portion of variance both for ECApp and extreme frequency, except for extreme precipitation, which is inherently noisier, showing that these SVD pairs are not simply dominated by variations in ECApp. The relationship between these SVD modes and the EOFs of ECApp and extreme event frequencies are discussed in the supplemental material.
Figure 10a shows the normalized ECApp time series of these three leading SVD modes. It can be seen that the three curves are very similar; hence we take their average (solid line) and call it the first common mode. We hypothesize that there is a common physical factor in nature that can influence the three kinds of winter extreme events together. This physical factor can be the variability of regional storm track, or some other factors that may affect storm track over North America. In Fig. 10a, we also show the normalized (to unit variance) map-averaged ECApp (dashed line). The Pearson correlation between the first common mode and the map-averaged ECApp is 0.984. It is also obvious that the years corresponding to the largest (and smallest) 10 values in our first common mode are the same years as our previous 10 high-ECApp years (and 10 low-ECApp years) (Fig. 1a). For this reason, the composite difference patterns of our first common mode are identical to those shown in Fig. 5.

Apart from the first common mode, we have also found a second common mode, consisting of the second SVD mode between ECApp and extreme cold frequency (Figs. 11a,b), the third SVD mode between ECApp and extreme high wind frequency (Figs. 11c,d), and the third mode between ECApp and extreme precipitation (Figs. 11e,f). Note that for 30 degrees of freedom, a correlation of 0.35 is significant at the $5 \%$ level. We can see that patterns of the three homogeneous correlation maps of ECApp are very similar to each other (Figs. 11a,c,e): a maximum over central

TABLE 2. As in Table 1, but for 850-hPa wind speed and histograms shown in Fig. 7 and Fig S3.

\begin{tabular}{|c|c|c|c|c|c|c|}
\hline \multirow[b]{2}{*}{$\begin{array}{l}\text { Locations selected for } \\
\text { wind speed at } 850 \mathrm{hPa}\end{array}$} & \multicolumn{2}{|c|}{ High composite } & \multicolumn{2}{|c|}{ Low composite } & \multicolumn{2}{|c|}{ Composite difference } \\
\hline & $\begin{array}{l}\text { Mean wind } \\
\left(\mathrm{m} \mathrm{s}^{-1}\right)\end{array}$ & Extreme counts & $\begin{array}{l}\text { Mean wind } \\
\left(\mathrm{m} \mathrm{s}^{-1}\right)\end{array}$ & Extreme counts & $\begin{array}{c}\text { Mean wind } \\
\left(\mathrm{m} \mathrm{s}^{-1}\right)\end{array}$ & Extreme counts \\
\hline Indiana $\left(40^{\circ} \mathrm{N}, 86.25^{\circ} \mathrm{W}\right)$ & 12.68 & 57 & 11.18 & 11 & 1.50 & 46 \\
\hline Missouri $\left(37.5^{\circ} \mathrm{N}, 90^{\circ} \mathrm{W}\right)$ & 12.27 & 51 & 11.03 & 19 & 1.24 & 32 \\
\hline Illinois $\left(40^{\circ} \mathrm{N}, 90^{\circ} \mathrm{W}\right)$ & 12.32 & 55 & 11.11 & 11 & 1.21 & 44 \\
\hline Ohio $\left(40^{\circ} \mathrm{N}, 82.5^{\circ} \mathrm{W}\right)$ & 12.96 & 61 & 11.44 & 15 & 1.52 & 46 \\
\hline Kentucky $\left(37.5^{\circ} \mathrm{N}, 86.25^{\circ} \mathrm{W}\right)$ & 12.80 & 64 & 11.10 & 14 & 1.70 & 50 \\
\hline Tennessee $\left(35^{\circ} \mathrm{N}, 86.25^{\circ} \mathrm{W}\right)$ & 12.62 & 59 & 11.05 & 20 & 1.57 & 39 \\
\hline
\end{tabular}


(a) Indiana, High(solid) \& Low(mesh) composite

(b) Missouri, High(solid) \& Low(mesh) composite
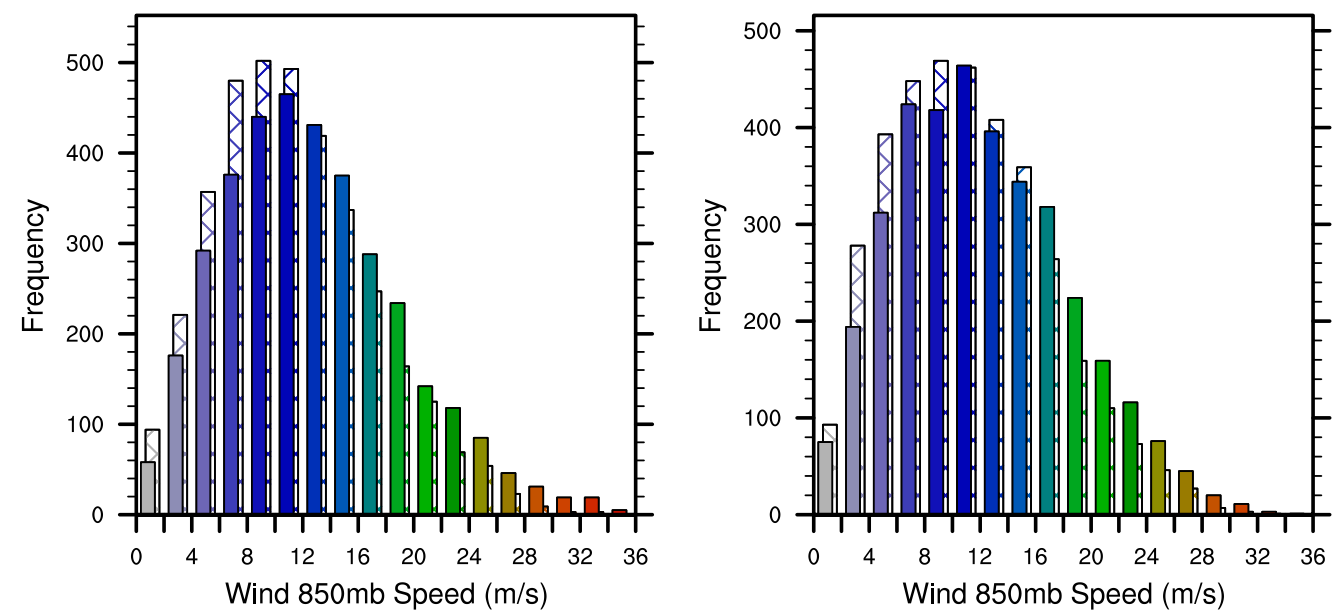

(c) Illinois, High(solid) \& Low(mesh) composite

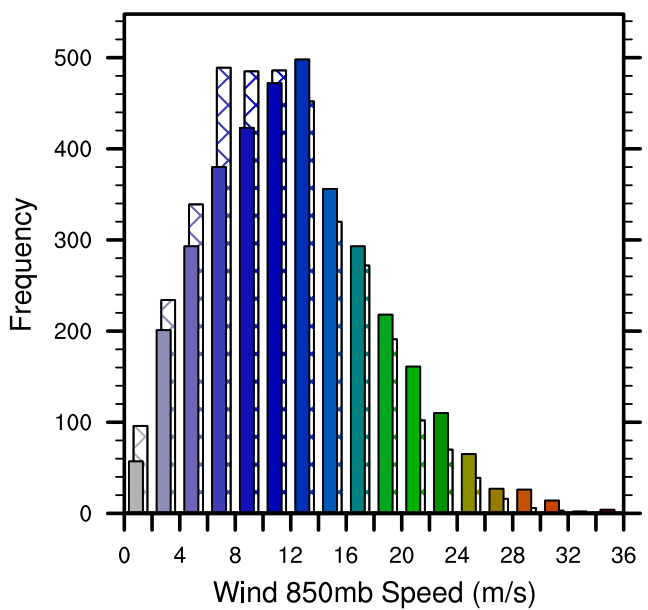

(d) Ohio, High(solid) \& Low(mesh) composite

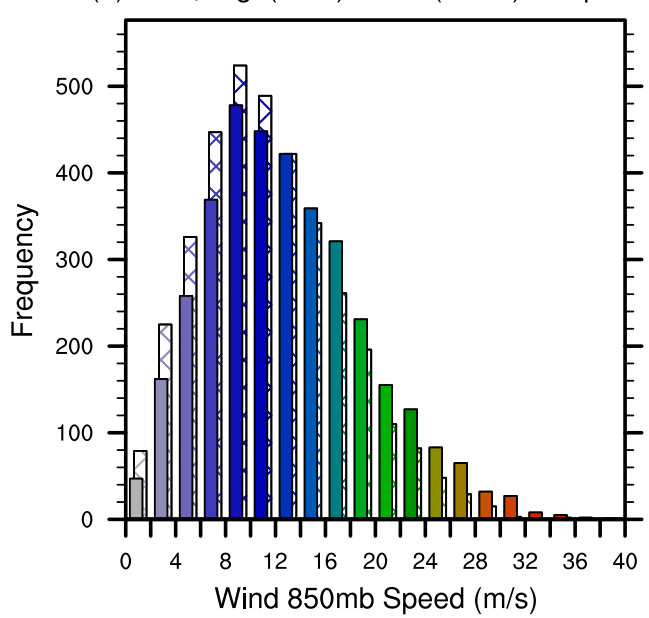

(e) Kentucky, High(solid) \& Low(mesh) composite

(f) Tennessee, High(solid) \& Low(mesh) composite
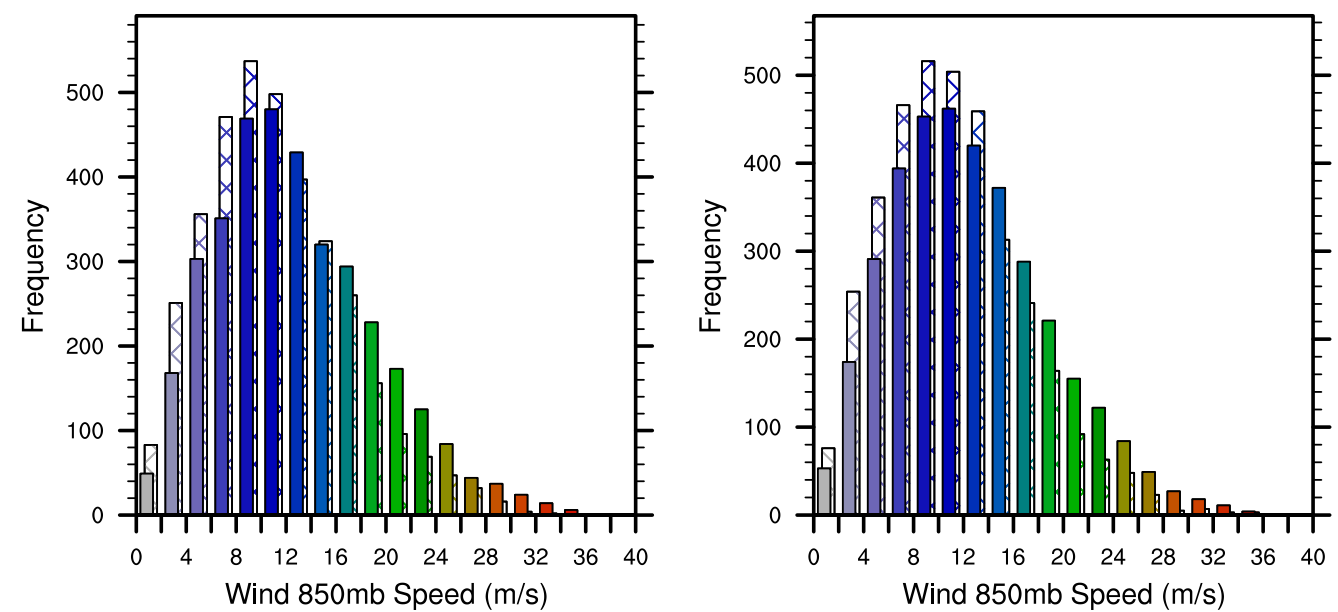

FIG. 7. Histograms of occurrence of $850-\mathrm{hPa}$ wind speed values, for high-ECApp years (solid bar) and lowECApp years (meshed non-solid bar) in (a) Indiana $\left(40^{\circ} \mathrm{N}, 86.25^{\circ} \mathrm{W}\right)$, (b) Missouri $\left(37.5^{\circ} \mathrm{N}, 90^{\circ} \mathrm{W}\right)$, (c) Illinois $\left(40^{\circ} \mathrm{N}\right.$, $\left.90^{\circ} \mathrm{W}\right)$, (d) Ohio $\left(40^{\circ} \mathrm{N}, 82.5^{\circ} \mathrm{W}\right)$, (e) Kentucky $\left(37.5^{\circ} \mathrm{N}, 86.25^{\circ} \mathrm{W}\right)$, and (f) Tennessee $\left(35^{\circ} \mathrm{N}, 86.25^{\circ} \mathrm{W}\right)$. Note that for 6-hourly wind, the top $1 \%$ for the whole 32 -yr period corresponds to 115 events, within which the contributions of high and low composites are shown in Table 2. 
Indiana-Ohio, High(solid) \& Low(mesh) composite

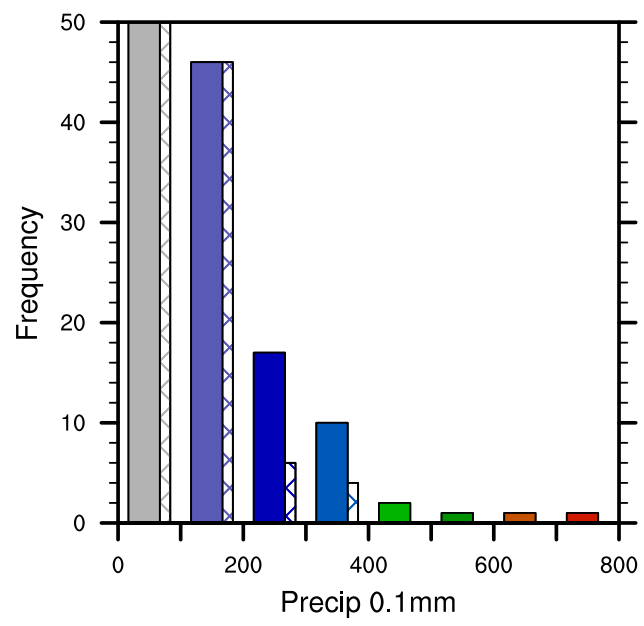

N. Michigan, High(solid) \& Low(mesh) composite

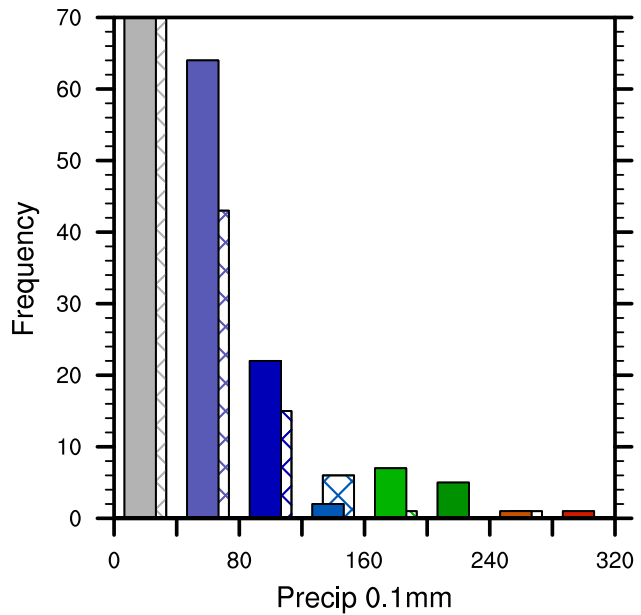

Texas, High(solid) \& Low(mesh) composite

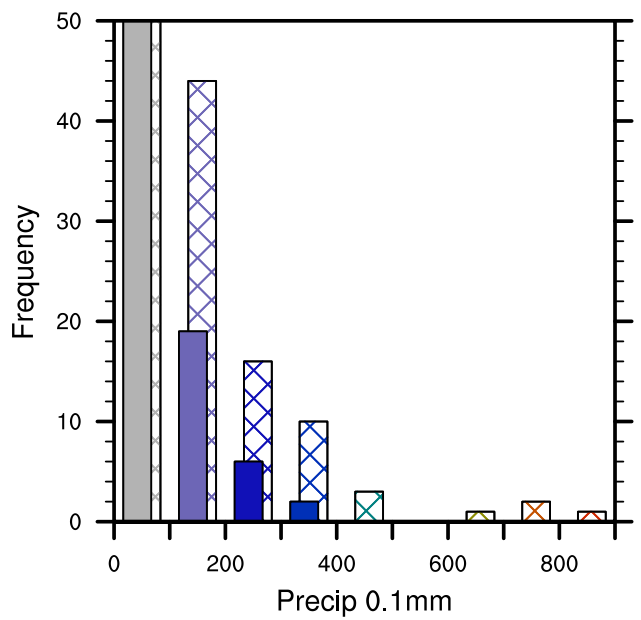

Montana-Idaho, High(solid) \& Low(mesh) composite

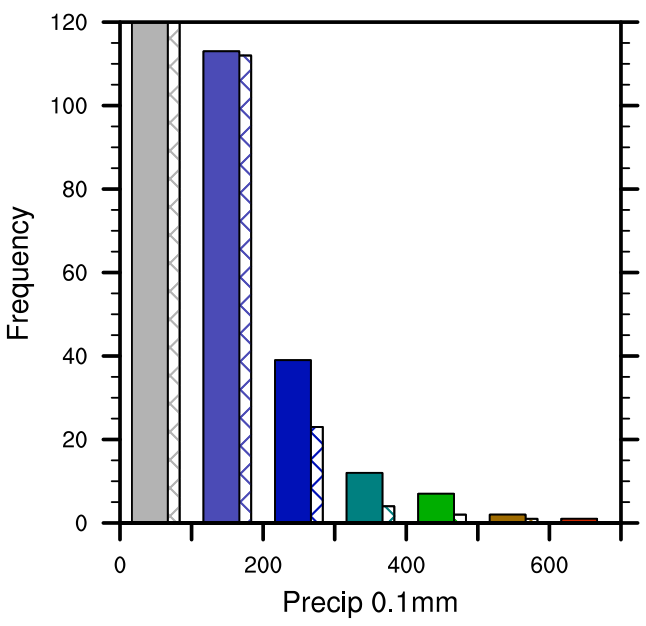

Washington, High(solid) \& Low(mesh) composite

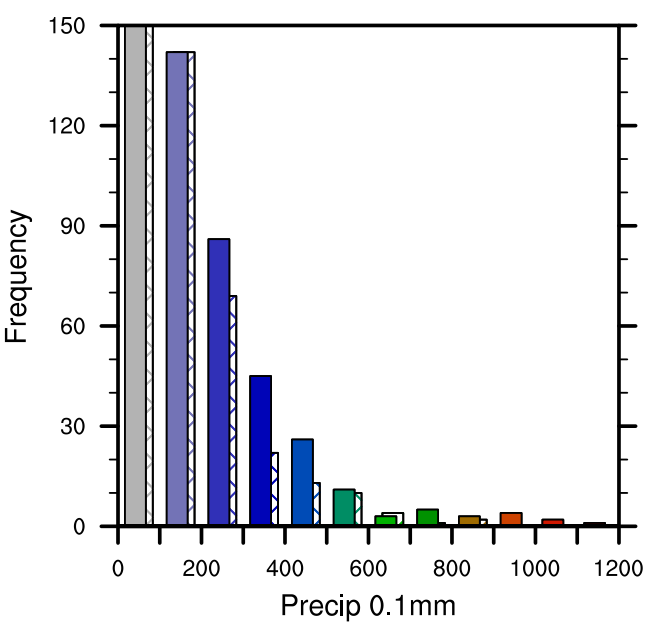

Florida, High(solid) \& Low(mesh) composite

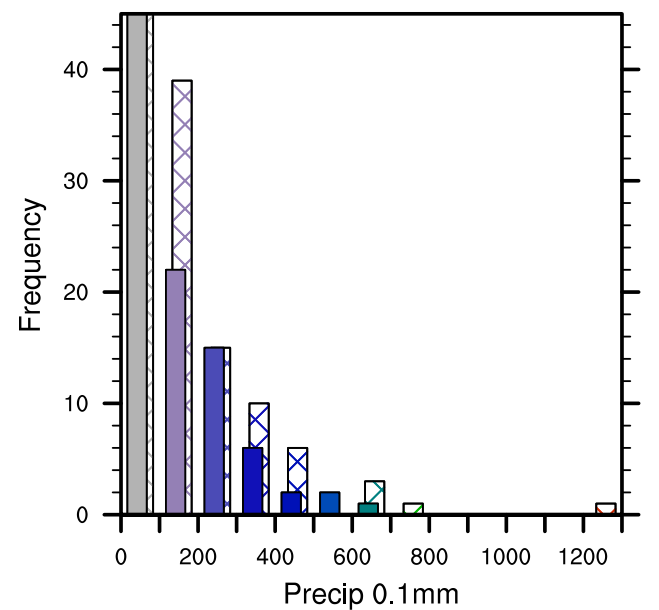

FIG. 8. Histograms of occurrence of precipitation values, for high-ECApp years (solid bar) and low-ECApp years (meshed non-solid bar), at (a) the Indiana-Ohio border $\left(39.875^{\circ} \mathrm{N}, 85.125^{\circ} \mathrm{W}\right)$, (b) the Montana-Idaho border $\left.\left(47.875^{\circ} \mathrm{N}, 116.125^{\circ} \mathrm{W}\right), \mathrm{c}\right)$ northern Michigan $\left(44.625^{\circ} \mathrm{N}, 84.625^{\circ} \mathrm{W}\right)$, (d) Washington $\left(46.875^{\circ} \mathrm{N}, 121.625^{\circ} \mathrm{W}\right)$, (e) Texas $\left(29.875^{\circ} \mathrm{N}, 98.125^{\circ} \mathrm{W}\right)$, and (f) Florida $\left(27.875^{\circ} \mathrm{N}, 82.125^{\circ} \mathrm{W}\right)$. Note that for daily precipitation, the top $1 \%$ for the whole 32 -yr period corresponds to 28 events, within which the contributions of high and low composites are shown in Table 3. 
TABLE 3. As in Table 1, but for precipitation amount and histograms shown in Fig. 8 and Fig S4.

\begin{tabular}{|c|c|c|c|c|c|c|}
\hline \multirow[b]{2}{*}{$\begin{array}{l}\text { Locations selected for } \\
\text { precipitation amounts on surface }\end{array}$} & \multicolumn{2}{|c|}{ High composite } & \multicolumn{2}{|c|}{ Low composite } & \multicolumn{2}{|c|}{ Composite difference } \\
\hline & $\begin{array}{l}\text { Mean precip } \\
(0.1 \mathrm{~mm})\end{array}$ & Extreme counts & $\begin{array}{l}\text { Mean precip } \\
\quad(0.1 \mathrm{~mm})\end{array}$ & Extreme counts & $\begin{array}{l}\text { Mean precip } \\
\quad(0.1 \mathrm{~mm})\end{array}$ & Extreme counts \\
\hline $\begin{array}{l}\text { Indiana-Ohio } \\
\qquad\left(39.875^{\circ} \mathrm{N}, 85.125^{\circ} \mathrm{W}\right)\end{array}$ & 323.9 & 17 & 300.1 & 6 & 23.8 & 11 \\
\hline $\begin{array}{l}\text { Montana-Idaho } \\
\quad\left(47.875^{\circ} \mathrm{N}, 116.125^{\circ} \mathrm{W}\right)\end{array}$ & 300.3 & 18 & 283.4 & 6 & 16.9 & 12 \\
\hline $\begin{array}{l}\text { Michigan } \\
\quad\left(44.625^{\circ} \mathrm{N}, 84.625^{\circ} \mathrm{W}\right)\end{array}$ & 163.1 & 14 & 144.9 & 4 & 18.2 & 10 \\
\hline Washington $\left(46.875^{\circ} \mathrm{N}, 121.625^{\circ} \mathrm{W}\right)$ & 373.4 & 16 & 337.8 & 4 & 35.6 & 12 \\
\hline Texas $\left(29.875^{\circ} \mathrm{N}, 98.125^{\circ} \mathrm{W}\right)$ & 265.2 & 2 & 352.5 & 20 & -87.3 & -18 \\
\hline Florida $\left(27.875^{\circ} \mathrm{N}, 82.125^{\circ} \mathrm{W}\right)$ & 319.9 & 8 & 384.8 & 13 & -64.9 & -5 \\
\hline
\end{tabular}

southern Canada, a minimum over the northeastern coast of the United States, and another minimum extending from the eastern Pacific into Oregon and Northern California. As for the heterogeneous correlation maps, for extreme cold, Fig. 11b shows a dipole structure that is northeast-southwest oriented, resembling to certain extent the dipole structure of the 2013/14 extreme winter (Hartmann 2015). The reduction in extreme cold frequency over northeastern United States is consistent with reduction in cyclone activity along the East Coast, but the increase over the Southwest is not clearly related to the change in cyclone activity over that region. For extreme wind, Fig. 11d shows a pattern similar to the homogeneous map of ECApp (Fig. 11c), implying the close relationship between the extreme wind and cyclone activity in winter. Finally, Fig. 11f shows the heterogeneous pattern of extreme precipitation, where the negative anomalies over the East Coast and the northwestern United States show a consistent relationship between the precipitation and cyclone activity, but overall the pattern is noisy.

For these three SVDs, the second mode between ECApp and extreme cold explains $15.6 \%$ of the SCF, $8.0 \%$ variance of ECApp, and $16.3 \%$ variance of the top first-percentile cold events frequency. The third mode between ECApp and extreme high wind explains $5.45 \% \mathrm{SCF}, 10.6 \%$ variance of ECApp, and $6.7 \%$ variance of the top first-percentile high wind frequency. And the third mode between ECApp and extreme precipitation explains $8.3 \%$ SCF, $10.3 \%$ variance of ECApp, and $4.3 \%$ variance of top first-percentile precipitation frequency. Figure 10b shows the ECApp time series of these three SVD modes. Even though they are not as consistent as the first common mode (Fig. 10a), they are still highly correlated (average correlation of 0.89). Because of this, we also take the average of these three ECApp time series and call it the second common mode.
To further explore the second common mode, the difference between the high and low composites (based on Fig. 10b) is shown in Fig. 12 (formatted in the same way as in Fig. 5). We can see that the anomalies in storm track (Fig. 12e) and extreme cold frequency (Fig. 12b) are quite strong. Its influence on extreme high wind frequency is also found to be significant (Fig. 12d). These composite differences show very similar patterns as their corresponding correlation maps (Fig. 11). However, for the extreme precipitation, even though its composite difference (Fig. 12f) is quite similar to its correlation map (Fig. 11f), the significant area is very small.

It is of interest to note that the composite difference of the mean minimum temperature is not significant (Fig. 12a), implying that the dipole structure of the extreme cold frequency is totally contributed by changes in the PDF and has little to do with the mean-state variations. For the composite difference of mean flow speed (Fig. 12c), the maximum in southern Canada coincides with the maximum of storm track there (Fig. 12e), making it possible that both the mean flow and storm track simultaneously influence the extreme wind frequency there (Fig. 12d). However, over much of the United States, the mean flow does not show significant differences, so the significant difference in extreme wind frequency is probably only related to the storm-track variations (Fig. 12e). As mentioned above, a detailed discussion on how these SVD modes relate to EOFs of the individual fields can be found in the supplemental material.

\section{Discussion}

\section{a. Relations to teleconnections}

\section{1) FIRST COMMON MODE}

What is the physical factor behind the two common modes: do they just reflect local U.S. storm-track variations, or are they affected by large-scale teleconnections, 
(a) Homo PP from SVD (PP, Extreme_Cold) 1st

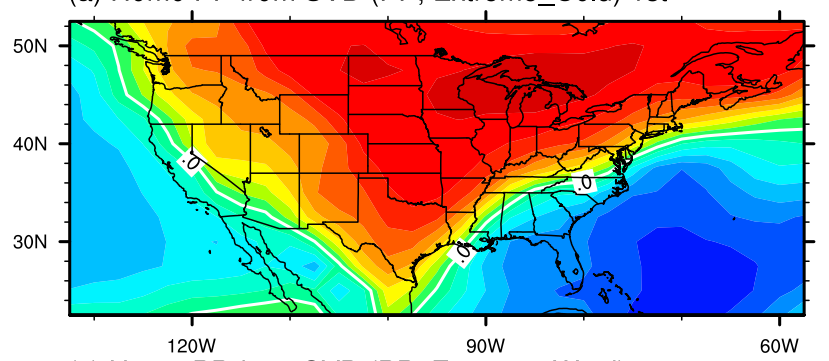

(c) Homo PP from SVD (PP, Extreme_Wind) 1st

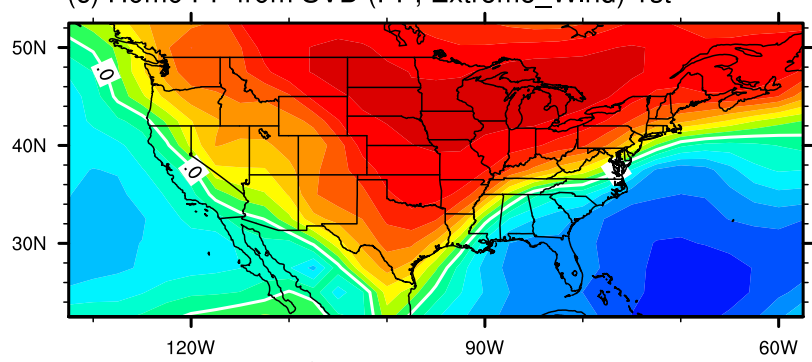

(e) Homo PP from SVD (PP, Extreme_Precip) 1st

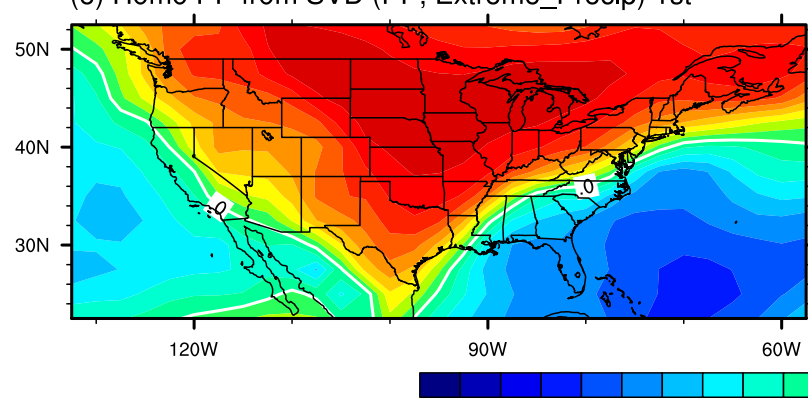

(b) Hetero Cold from SVD ( PP, Extreme Cold) 1st

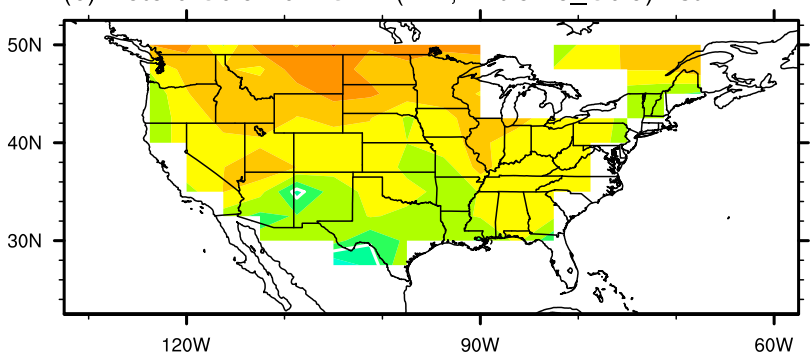

(d) Hetero Wind from SVD (PP, Extreme_Wind) 1st

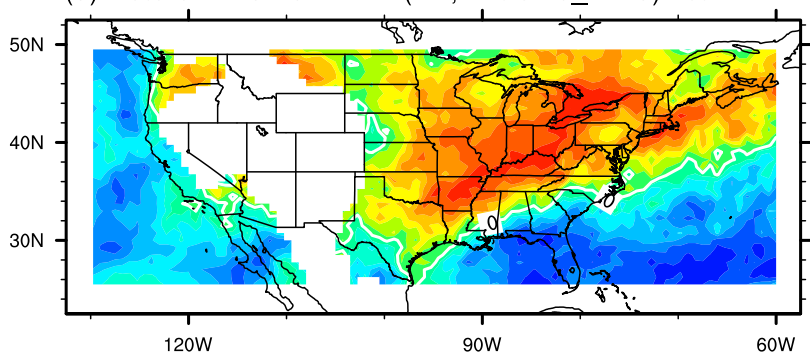

(f) Hetero Precip from SVD (PP, Extreme_Precip) 1st

\section{$\begin{array}{lllllllll}-0.8 & -0.6 & -0.4 & -0.2 & 0 & 0.2 & 0.4 & 0.6 & 0.8\end{array}$}

FIG. 9. The first common SVD mode pattern. (a) Homogeneous correlation map of ECApp from the first SVD mode between ECApp and 99th percentile extreme cold events frequency. (b) Heterogeneous correlation map of extreme cold frequency, from the first SVD mode between ECApp and 99th percentile extreme cold events frequency. (c),(d) As in (a),(b), but for high wind frequency and the region where the surface pressure has consistently been below $850 \mathrm{hPa}$ has been masked out in (d). (e),(f) As in (a),(b) but for heavy precipitation frequency. The correlation coefficient between the left and right time series from the first SVD mode between ECApp and the extreme cold, wind, and precipitation events frequency is $0.46,0.84$, and 0.89 , respectively.

such as ENSO, the PNA pattern, or the NAO? To answer this question, we used our first common mode time series to perform a Pearson correlation with the 500-hPa geopotential height (Fig. 13a) and the SST (Fig. 13c). The correlation pattern in Fig. 13a shows some features of the negative phase of the PNA pattern, as described by previous studies (Wallace and Gutzler 1981; Dickson and Namias 1976; Namias 1978): the two maximum regions, one stretching from the central Pacific to the west coast of the United States and the other extending from the southern United States toward the middle Atlantic, are separated by a negative anomaly over Canada. In Fig. 13c, the cold tongue region extending from the equatorial eastern Pacific to the central Pacific clearly shows the relationship between the first common mode and the negative phase of El Niño-Southern Oscillation (ENSO), or La Niña (Philander 1985 and 1990). Since the
PNA pattern can be influenced greatly by external forcings including ENSO (Horel and Wallace 1981), it is not surprising that our first common mode can be associated with both of these factors. Note that the correlation between the first common mode time series and the Niño3.4 index is -0.57 , while its correlation with the PNA index is -0.60 (Table 4 ).

Given that there exist strong relationships between our first common mode and the negative phase of the PNA pattern and ENSO, the composites shown in Fig. 5 reflect many features related to the two teleconnections. For example, previous studies suggested that El Niño is associated with enhanced cyclone development over the Gulf of Mexico and southeastern United States and reduced cyclone development over the Great Lakes and northern Great Plains (Noel and Changnon 1998; Hirsch et al. 2001; Eichler and Higgins 2006), and La Niña 

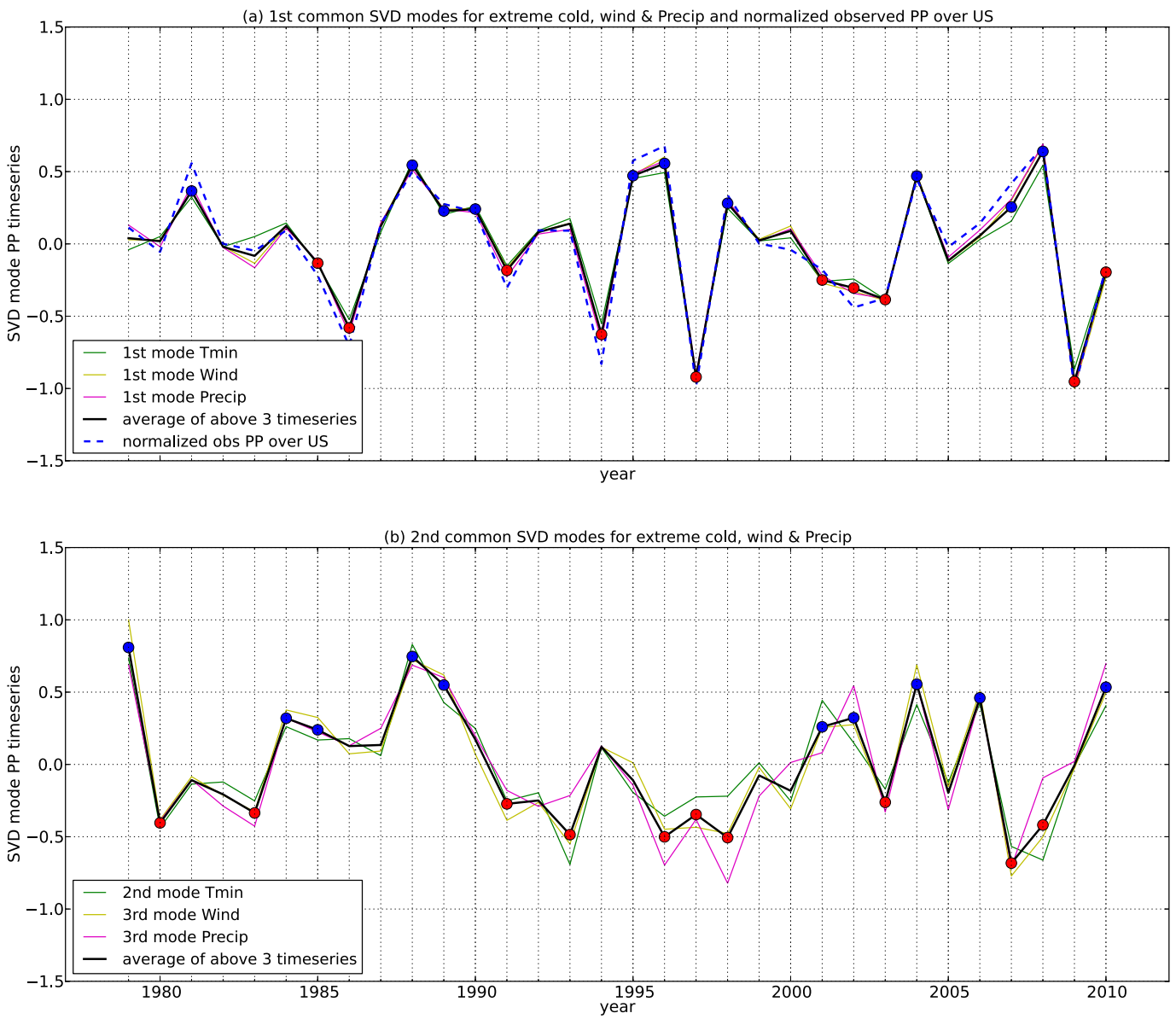

FIG. 10. (a) The normalized ECApp time series of the three leading SVD modes are shown as the three thin lines: Tmin (green), wind (greenish yellow), and precipitation (purple). The average of the three time series is regarded as the first common mode, which is shown as the solid black line. The map-averaged ECApp is normalized onto the same magnitude as the first common mode and is shown as the dashed blue line. For the first common mode, the largest $10 \mathrm{yr}$ are indicated by blue dots and the smallest $10 \mathrm{yr}$ by red dots. (b) As in (a), but for the second common SVD mode.

winters are associated with modest increases in cyclone tracks and development in the Great Lakes region and northern Great Plains (Kunkel and Angel 1999; Grise et al. 2013). Similarly, for the PNA pattern, the positive phase is associated with enhanced cyclone tracks and development over the southeastern United States, and the negative phase is associated with enhanced cyclone tracks and development over the Great Lakes (Leathers et al. 1991; Angel and Isard 1998). In Fig. 5e, by comparing the ECApp around the Great Lakes and the northern Great Plains with the southeastern coast, the storm-track difference is consistent with these previous results. For winter precipitation, El Niño winters exhibit a coherent large-scale pattern with below average snowfall across approximately the northern half of the United States, and above average snowfall over the southwestern United States, whereas La Niña winters show above normal snowfall in northwestern United States and northern Great Lakes (Kunkel and Angel 1999). During either high-PNA-pattern or El Niño winters, more moisture is transported to the central United States (which results in more precipitation there), but less moisture is transported into the Ohio River valley (less precipitation there) from the Gulf of Mexico (Ning and Bradley 2015). In Fig. 5f, the most significant signal is the maximum in the Ohio River valley, comparing with the below average extreme precipitation frequency in Texas, the southwestern United States, and the East Coast. Hence the difference in the frequency of extreme precipitation is generally consistent with what these previous studies described. For extreme temperature, either the highPNA-pattern or El Niño winters are related to more winter warm extreme days and less cold extreme days 
(a) Homo PP from SVD (PP, Extreme_Cold) 2nd

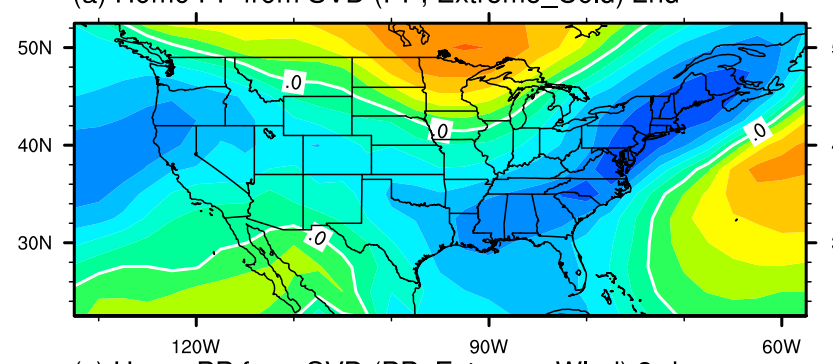

(c) Homo PP from SVD (PP, Extreme_Wind) 3rd

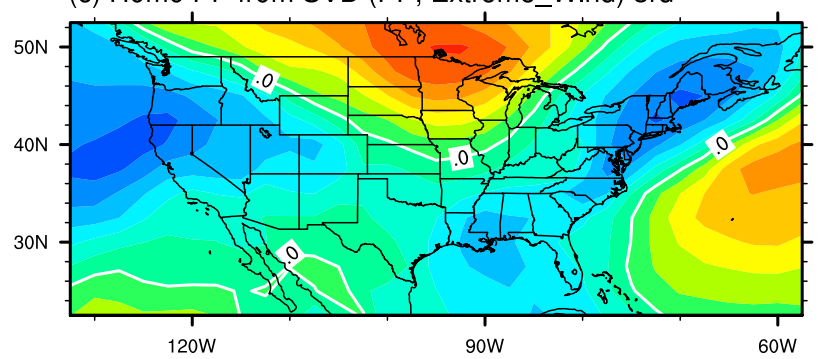

(e) Homo PP from SVD (PP, Extreme Precip) 3rd

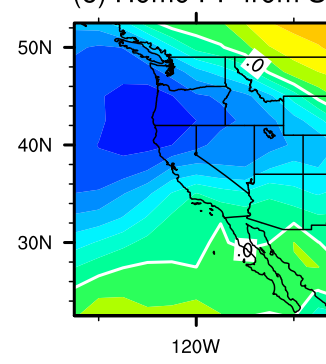

(b) Hetero Cold from SVD ( PP, Extreme Cold) 2nd

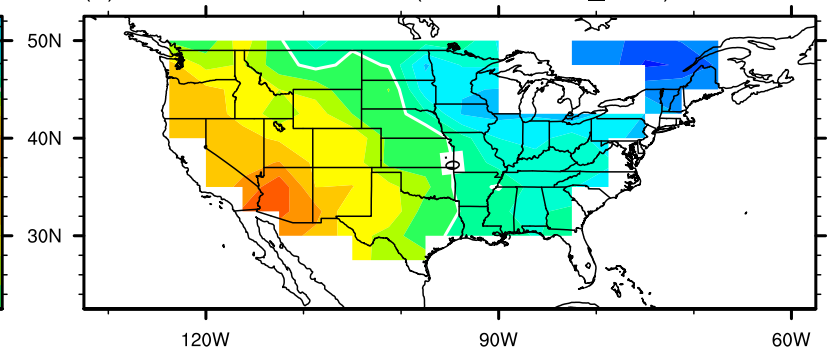

(d) Hetero Wind from SVD (PP, Extreme_Wind) 3rd

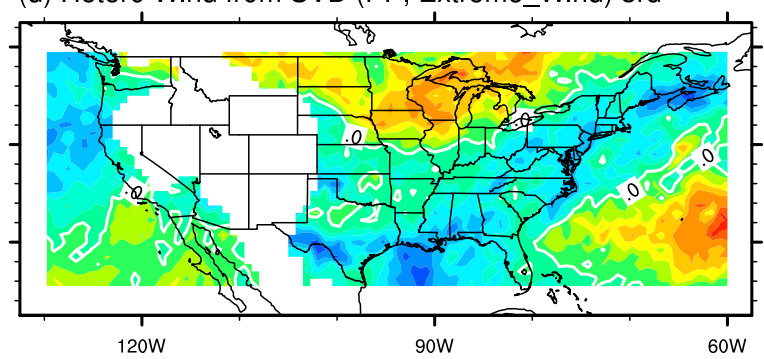

(f) Hetero Precip from SVD (PP, Extreme_Precip) 3rd

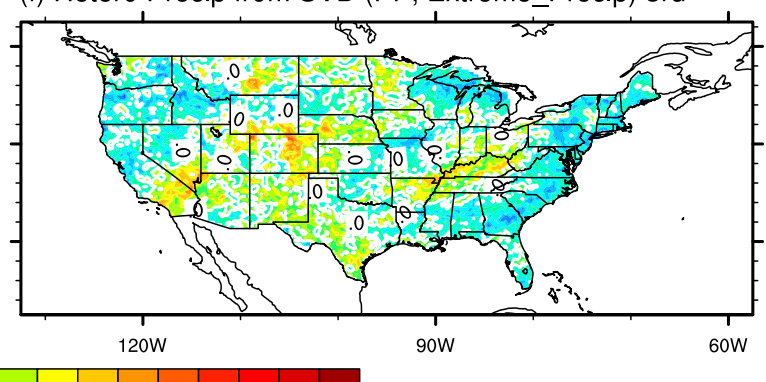
\begin{tabular}{llllll|l|l|l|l|l|l|l|l}
-0.8 & -0.6 & -0.4 & -0.2 & 0 & 0.2 & 0.4 & 0.6 & 0.8
\end{tabular}

FIG. 11. As in Fig. 9, but for the second common SVD mode. The correlation coefficient between the left and right time series from the second (or third, or third) SVD mode between ECApp and the extreme cold (or wind, or precipitation) events frequency is 0.67 (or 0.83 , or 0.88 , respectively).

in the United States (Ning and Bradley 2015). So the overall increase in extreme cold frequency shown in Fig. $5 \mathrm{~b}$ is also consistent.

Since both the correlation patterns (Fig. 13) and the composite difference (Fig. 5) imply that the mode we found is associated with the negative phase of ENSO and PNA pattern, it is of interest to see the composite differences based on these two teleconnections. We have used the PNA index and the Niño-3.4 index to compute high and low composites. Figure 14 shows the composite differences based on the negative of the PNA index. The results are quite similar to Fig. 5, but some clear differences can be seen. In Fig. 14e, the anomaly of ECApp in the central United States (the Great Lakes) is shown to be about $10(20) \mathrm{hPa}^{2}$ smaller than that shown in Fig. 5e, but the negative signal in the eastern Pacific is much stronger. The difference in mean minimum temperature shown in Fig. 14a has a similar magnitude as for ECApp (Fig. 5a), but the minimum region extends much farther westward. As for extreme cold frequency, in the northwestern United States and southwestern Canada the value in Fig. $14 \mathrm{~b}$ is at least $0.6 \%$ less than that shown in Fig. 5b. However, in Ohio, Indiana, and Kentucky, the values in Fig. $5 b$ are slightly smaller (by about $0.3 \%-0.6 \%$ ) than those in Fig. 14b. By comparing Figs. $5 \mathrm{~d}$ and $14 \mathrm{~d}$, we can see that the difference in extreme high wind frequency is about $0.6 \%-0.9 \%$ weaker in the composite based on the PNA index in the Ohio River valley region, but $0.3 \%-0.6 \%$ stronger in Wisconsin and its surrounding regions. Finally, for extreme precipitation frequency difference, the PNA composite (Fig. 14f) shows almost no significant region except for Florida.

Figure 15 shows the composite differences based on the negative of the Niño-3.4 index. The composite difference patterns of the mean minimum temperature (Fig. 15a) and the mean flow (Fig. 15c) here are generally similar to those in Fig. 5. Over much of the United States, the storm-track anomaly pattern (Fig. 15e) is only slightly weaker (about $5-10 \mathrm{hPa}^{2}$ ) than that in Fig. 5e, except along the northern border with Canada, 
(a) Mean Tmin difference

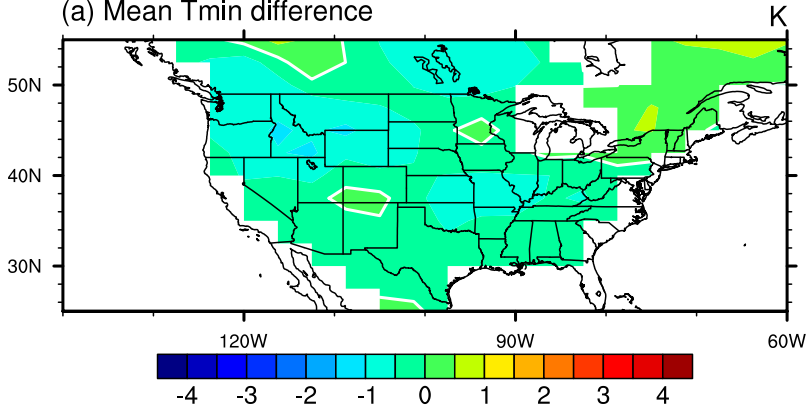

(c) Mean $850 \mathrm{mb}$ Wind Speed difference

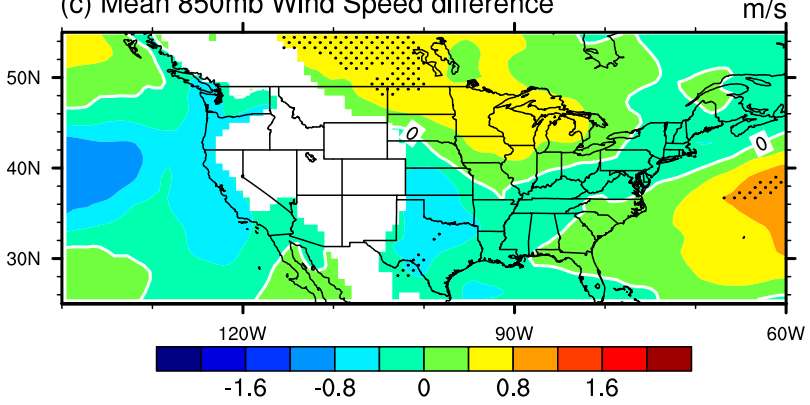

(e) Mean ECApp difference

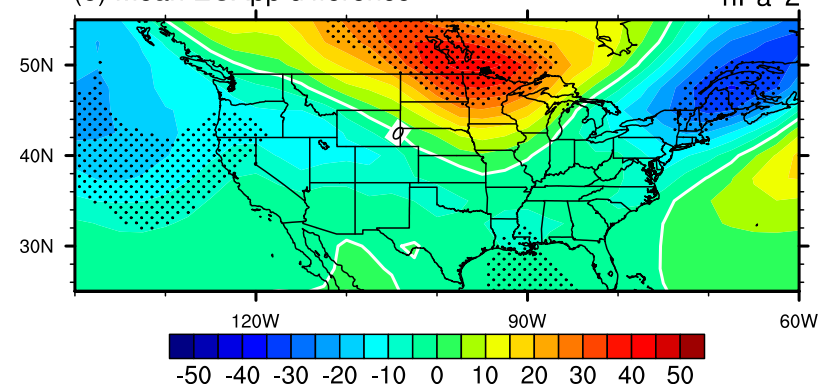

(b) $99 \%-$ Tmin frequency difference

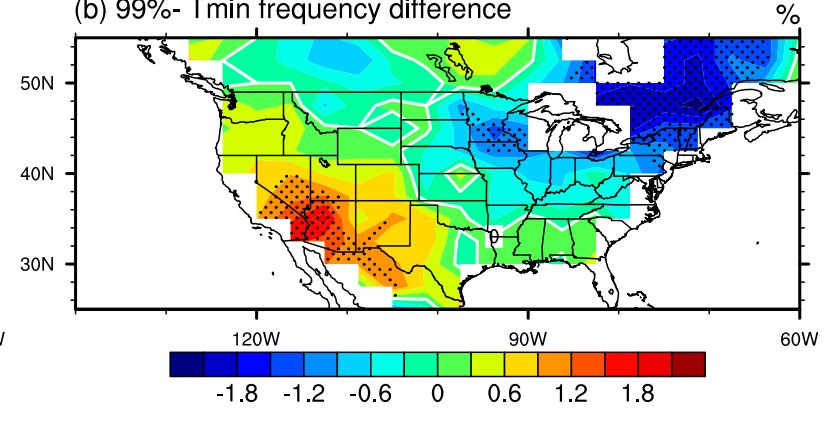

(d) $99 \%$ - high wind frequency difference

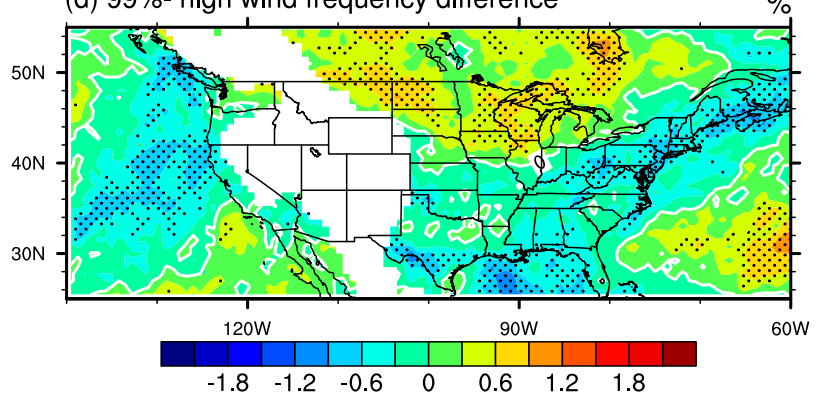

(f) $99 \%$ - Precip frequency difference

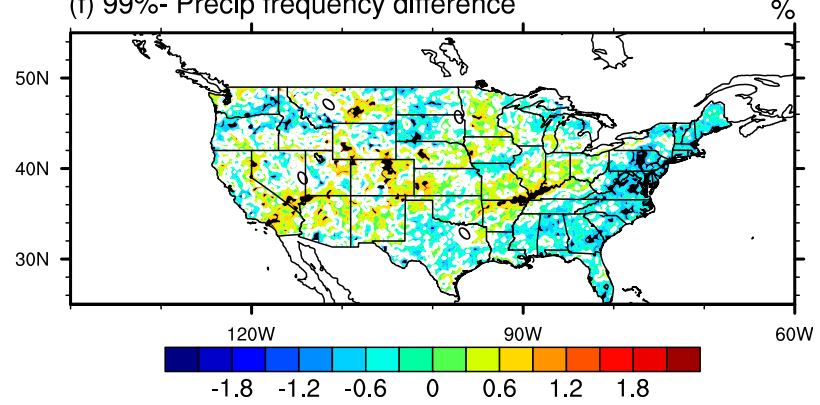

FIG. 12. As in Fig. 5, but for the second common SVD mode.

where the value is about $10-20 \mathrm{hPa}^{2}$ smaller than in Fig. 5e. However, as for extreme cold, the magnitude of the values and the extent of significant locations in Fig. 15b are even less than those in Fig. 14b, and hence much smaller than in Fig. 5b. For the difference of extreme high wind frequency (Fig. 15d), the significant area is quite large but the value is much (about $0.6 \%$ ) smaller than the maximum region found in Fig. $5 \mathrm{~d}$. However, for precipitation, even though the extreme precipitation frequency difference is not significant in the Great Lakes region, the minimum regions in the southwestern United States, Texas, and the East Coast become much more significant in Fig. 15f, showing a strong relationship between the El Niño events and winter precipitation over the southern United States.

Since the NAO is also a dominant climate variability in the NH (Wallace et al. 1988), we also used the NAO index from the CPC to make plots similar to those shown in Fig. 5. Shown in Fig. S10 of the supplemental material, the results do not resemble any previous figures we have seen, implying that the NAO is not closely related to our first common mode. And the correlation coefficient between these two time series is 0.34 , not significant at the $5 \%$ level.

Based on these results we conclude that even though much of the variability of storm track, extreme temperature, extreme high wind, and extreme precipitation over the United States is related to the PNA pattern and ENSO, there is a noticeable residual that is not associated with them.

\section{2) SECOND COMMON MOdE}

In the discussions above, we have seen that the extreme cold anomalies related to the second common mode exhibits a dipole structure (Figs. $11 \mathrm{~b}$ and 12b) similar to that found in the January-February 2014 extreme. The months of January and February in 2014 were an unusually cold and snowy time for the East 
(a) Corr(svd1, hgt500)

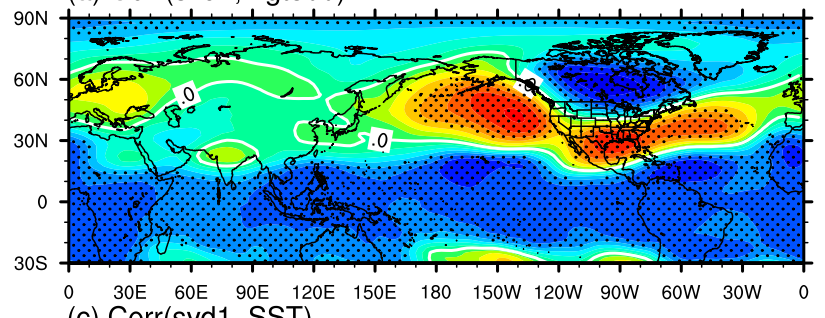

(b) Corr(svd2, hgt500)

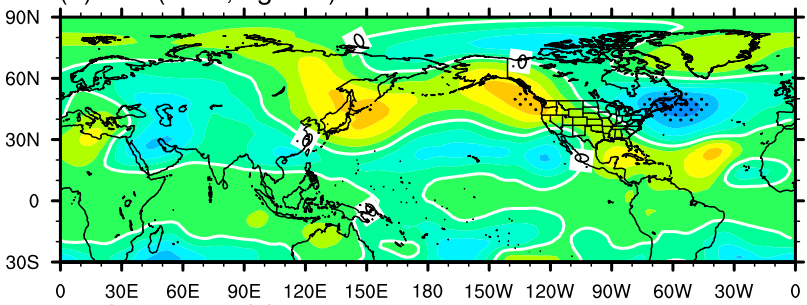

(d) $\operatorname{Co}$ Corr(SVd2, SST)

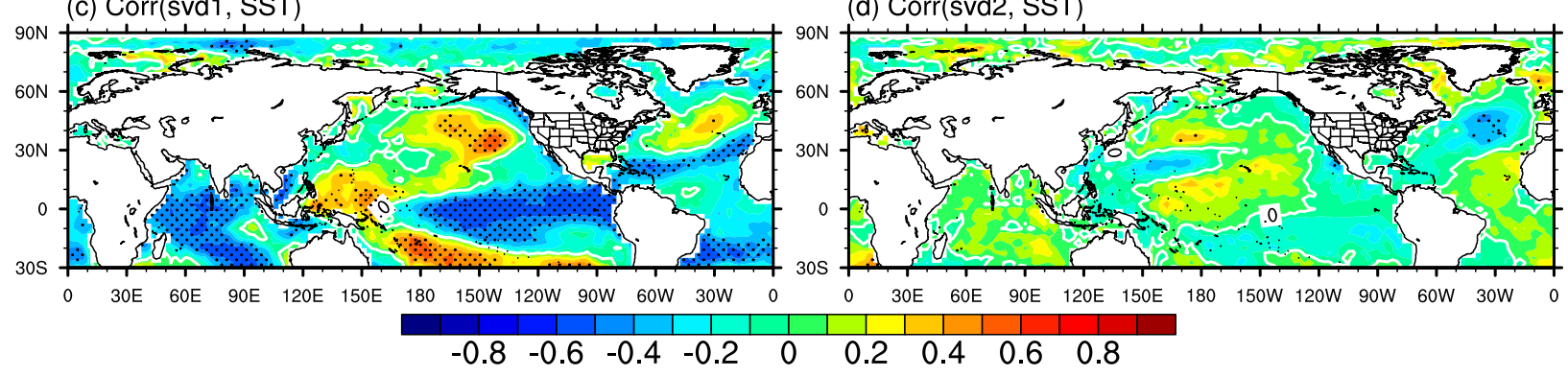

FIG. 13. Point-by-point correlation between 500-hPa geopotential height and the time series of the (a) first and (b) second common mode. (c),(d) As in (a),(b), but for SST. The dotted regions are regions where the correlation is significant at the $5 \%$ level.

Coast, while on the U.S. West Coast it was sunny and dry. According to Hartmann (2015), the 2013/14 winter pattern over the North America was associated with the North Pacific mode (NPM) of SST variations and was related to natural variability of the climate system. We have performed a point-by-point correlation between the second common mode time series and the geopotential height (Fig. 13b) and SST (Fig. 13d). The pattern in Fig. 13b does show a dipole structure between the East Coast and the West Coast; however, only the eastern part of the structure is statistically significant. In the central Pacific, the correlation with SST (Fig. 13d) shows little resemblance to the NPM pattern shown in Hartmann (2015), and the correlation is very weak. These results suggest that our second common mode is likely not strongly related to the NPM. The lack of strong correlations with remote SST or geopotential height suggests that this mode is likely a regional mode of internal climate variability. Note that the time series of the second common mode is not significantly correlated with the NAO, PNA, or Niño-3.4 indices (Table 4).

\section{b. Potential impacts of future ECApp change}

Since we have shown that storm-track variations have significant impacts on the frequency of extreme events over the United States, it is of interest to examine whether projected storm-track change under global warming may have impacts on the frequency of occurrence of extreme events. Under global warming, the wintertime storm track in North America is projected to significantly decrease (Chang et al. 2012; Chang 2013). The projected change of the storm track over North
America under global warming, based on ensemble mean change from 28 CMIP5 models, is shown in Fig. 16a. In the northern half of the United States, the reduction in ECApp ranges from 10 to $20 \mathrm{hPa}^{2}$ and is significant over most locations. To assess whether projected storm-track change may potentially impact the frequency of high-impact weather events, this change is multiplied by the regression coefficients between the observed ECApp and 99th percentile extreme events frequency at each grid point (Figs. 16b-d). Figure 16b shows the estimated reduction in 99th percentile extreme cold frequency. Given that the probability that a 99th percentile event happens is $1 \%$, in southwestern United States and southwestern Canada values close to $-0.3 \%$ or even $-0.4 \%$ suggest that this probability will drop from $1 \%$ to $0.7 \%$ or even $0.6 \%$, based on the current 99th percentile threshold. The dotted regions in Figs. 16b-d represent regions over which both the regression coefficients and the ensemble mean ECApp change are significant at the $5 \%$ level. Figure $16 \mathrm{c}$ shows the estimated reduction of 99th percentile extreme high wind frequency. Within several maximal regions, such as to the south and west of the Great Lakes, the reduction

TABLE 4. Pearson correlation between the time series of the two common SVD modes and the Niño-3.4, PNA, and NAO indices. The boldface values represent correlations that are significant at the $5 \%$ level.

\begin{tabular}{lcrr}
\hline \hline \multicolumn{1}{c}{ Correlation } & Niño-3.4 & PNA & NAO \\
\hline First common SVD mode & $\mathbf{- 0 . 5 7}$ & $\mathbf{- 0 . 6 0}$ & 0.34 \\
Second common SVD mode & 0.03 & -0.10 & -0.07 \\
\hline
\end{tabular}


(a) Mean Tmin comp. difference

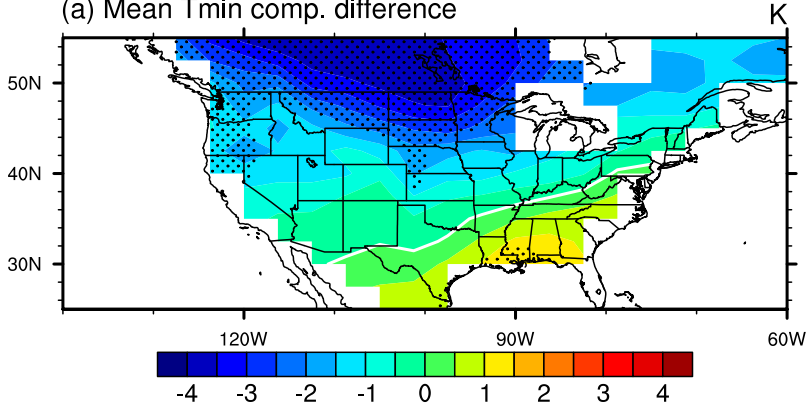

(c) Mean $850 \mathrm{mb}$ Wind Speed comp. difference

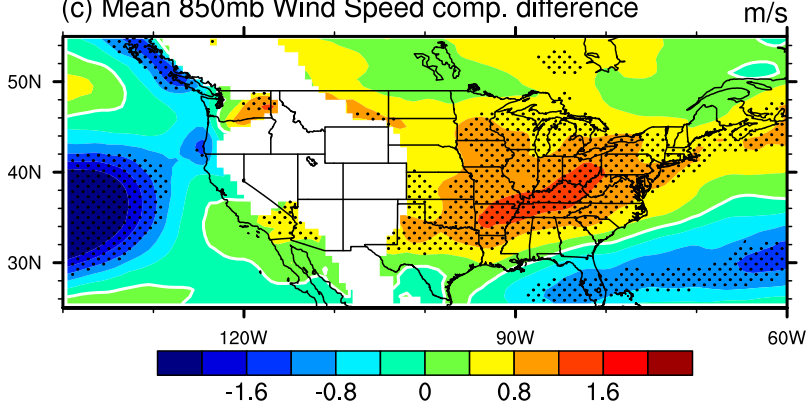

(e) Mean ECApp comp. difference

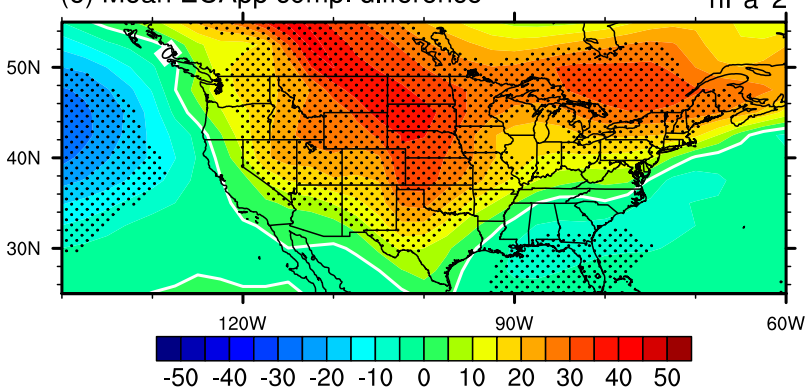

(b) 99\%- Tmin frequency comp. difference

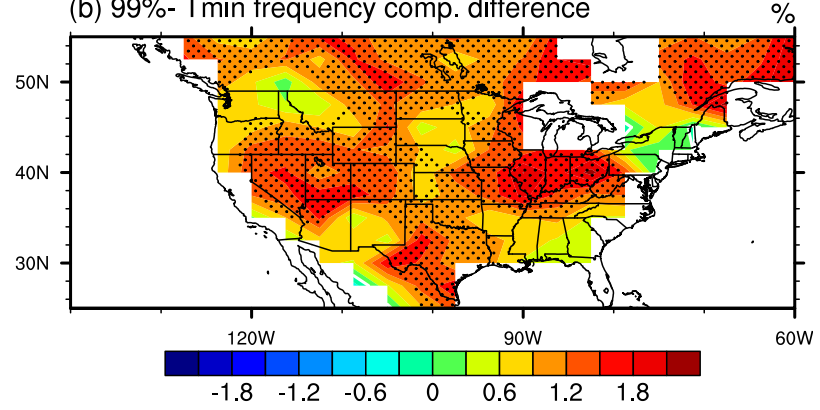

(d) $99 \%$ - high wind frequency comp. difference

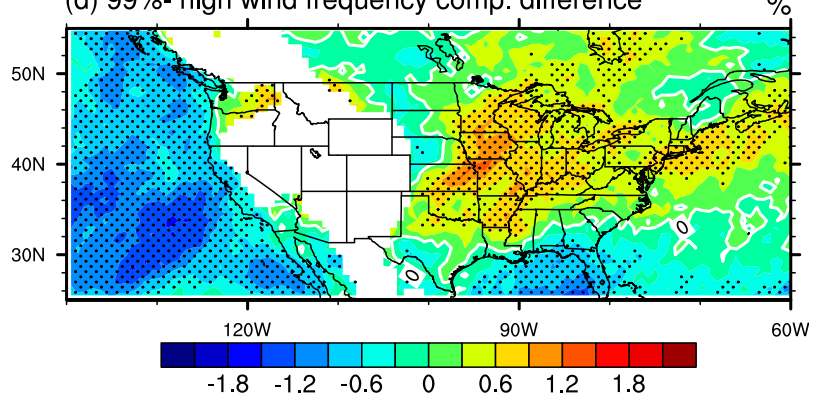

(f) $99 \%$ - Precip frequency comp. difference

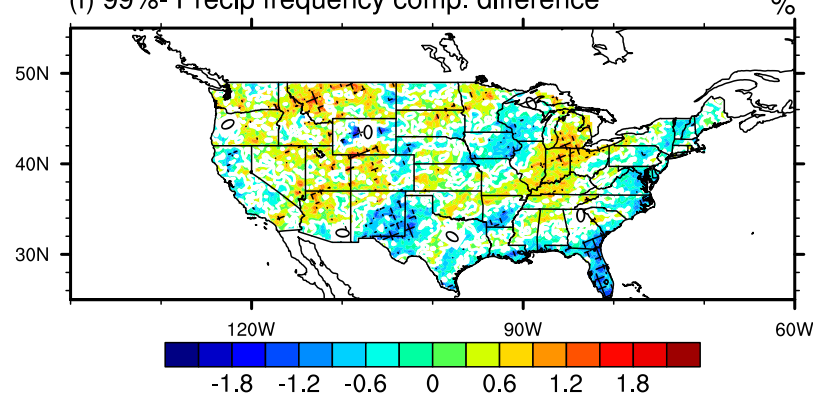

FIG. 14. As in Fig. 5, but using the negative of the PNA index to form the high and low composites.

is over $0.2 \%$. Finally, Fig. $16 \mathrm{~d}$ shows the estimated reduction of 99th percentile precipitation frequency, which suggests maximum reduction to the south and west of the Great Lakes, as well as over the Rockies. The reduction within these maximum changing areas is close to $0.15 \%$. Between these reduction regions, there is a positive area in the south central United States where the frequency of 99th percentile precipitation is projected to increase by up to $0.1 \%$. To show the robustness of the results, we have also performed the same regressions for the 95th percentile extreme events, which are shown in Fig S11 of the supplemental material. The patterns are almost the same as those shown in Fig. 16, and the values are almost proportional to the results shown there: the reduction in extreme cold frequency is up to $1.5 \%$, the reduction in extreme high wind frequency is up to $1.2 \%$, and the reduction in extreme precipitation is up to $0.75 \%$.

We would like to emphasize that Fig. 16 (and Fig. S11) only shows the estimated potential effects based on projected storm-track changes, and does not include the direct impacts of global warming. Our regressed reduction of extreme cold events will reinforce the warming of U.S. winters. But for precipitation, global warming will lead to more moisture transport into the higher latitudes and generally provide more precipitation there (Meehl et al. 2007; Held and Soden 2006; Chou and Neelin 2004; Seager et al. 2010; Kutzbach et al. 2005; Emori and Brown 2005). Our regressed reduction in the frequency of heavy precipitation events could partly offset this increase. It should also be noted that our estimates assume a stationary relationship between the extremes and cyclone activity in the changing climate. However, as global warming is going on, the impacts of storm-track variability on extreme events may be different from the historical period. In future studies, the physical processes behind the impact of the storm track on extreme events will be examined, and how these 
(a) Mean Tmin comp. difference

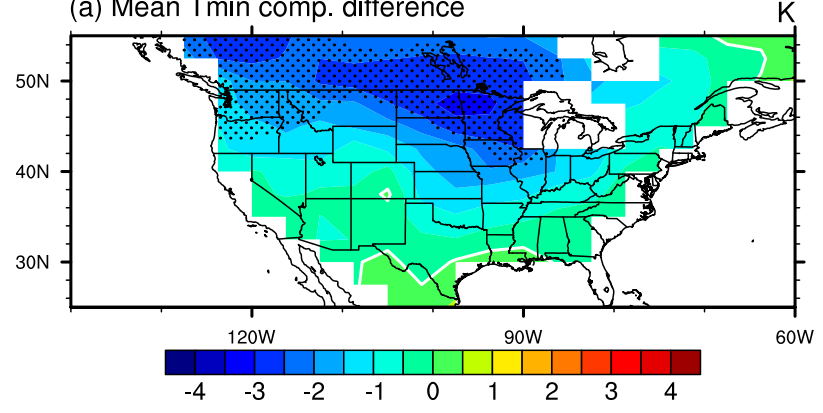

(c) Mean $850 \mathrm{mb}$ Wind Speed comp. difference

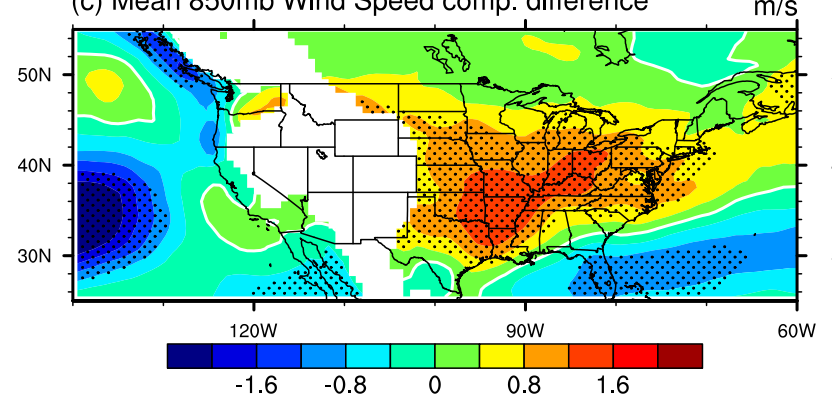

(e) Mean ECApp comp. difference

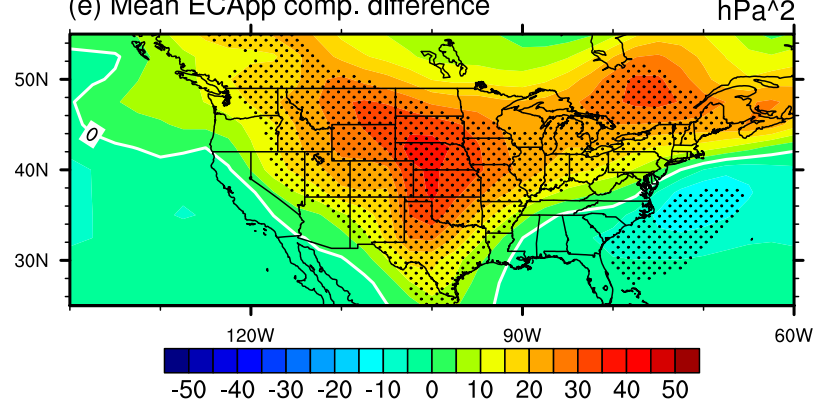

(b) $99 \%$ - Tmin frequency comp. difference

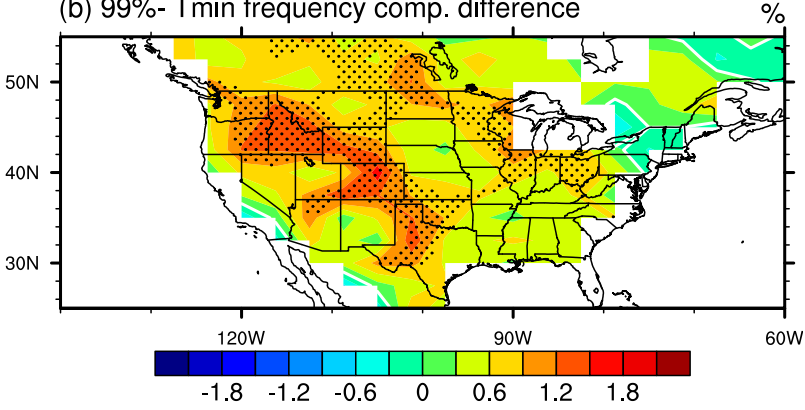

(d) $99 \%$ - high wind frequency comp. difference

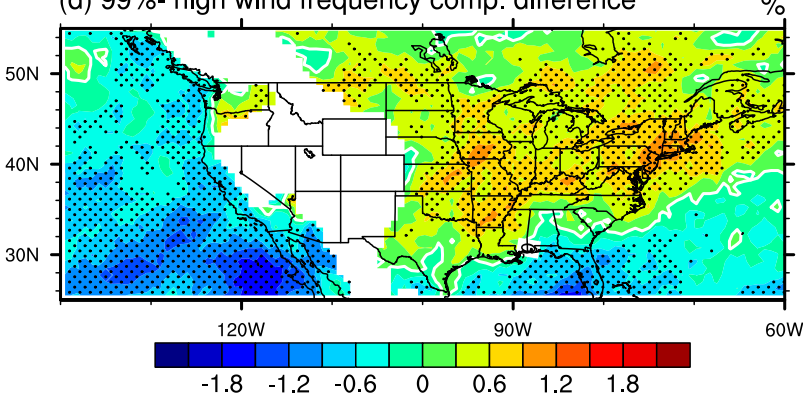

(f) $99 \%$ - Precip frequency comp. difference

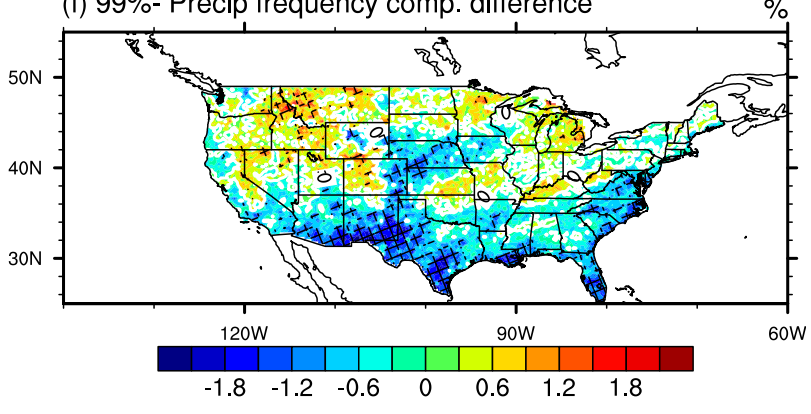

FIG. 15. As in Fig. 5, but using the negative of the Niño-3.4 index to form the high and low composites.

processes may change under global warming will be analyzed.

\section{Summary}

Previous studies have shown that storm-track variations have significant impacts on the occurrence of extreme cold temperature, extreme high wind, and heavy precipitation events over the United States during winter (e.g., Pfahl and Wernli 2012; Kunkel et al. 2012; Ashley and Black 2008). Nevertheless, these studies used different ways to define extreme events, as well as relate extremes to different cyclone statistics, making their results difficult to compare. Here we compare these impacts and examine how much these extremes are related through the cyclone activity by using the same cyclone statistics (ECApp) and the composite difference of extreme events frequency to show the impacts on all three kinds of extremes.
Using composites based on years with high and low storm-track activity averaged over the continental United States and southern Canada, our results show that all three kinds of extreme events are strongly modulated by storm-track variations. Nevertheless, our method cannot cleanly separate the impacts due to storm-track variations from the influence of mean-state variations. However, by directly examining the frequency distribution during the high and low storm-track years, we demonstrate that much of the changes in the frequency of extreme events are due to extension of the tail of the PDF rather than shift of the mean, directly confirming the impacts of storm-track variations.

To explore more regional impacts, we have performed three SVD analyses between cyclone activity and each kind of extreme event frequency separately. The results show that the leading modes of all three SVD analyses are associated with the overall increase or decrease of storm tracks over the United States. We take the 
(a) CMIP5 multi-model mean PP change

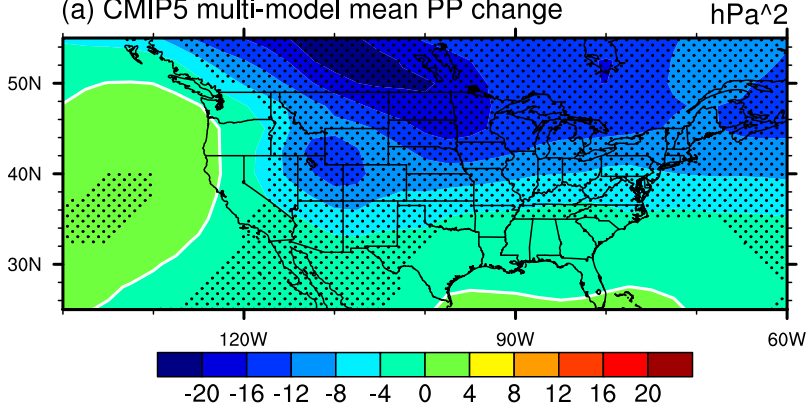

(c) 99th- percentile high wind frequency change

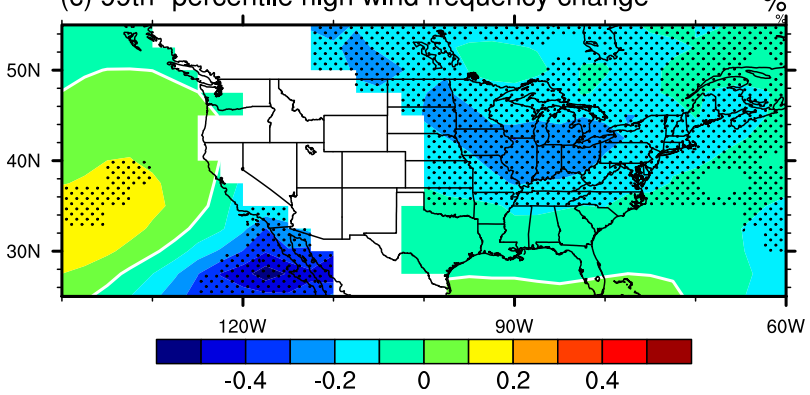

(b) 99th- percentile cold event frequency change

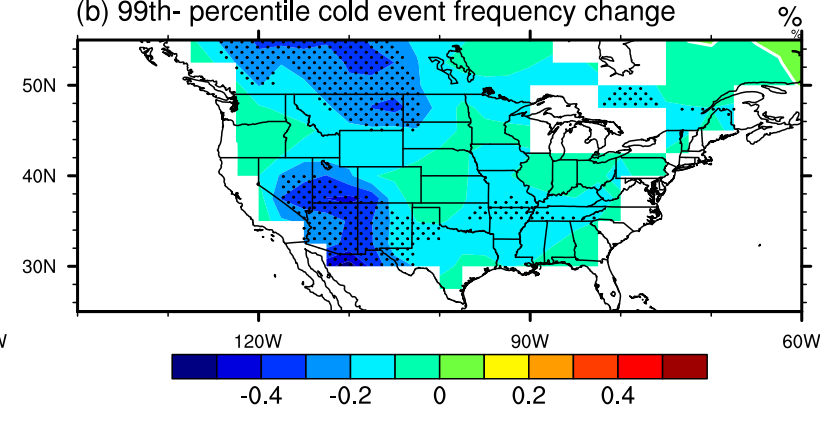

(d) 99th- percentile precipitation frequency change

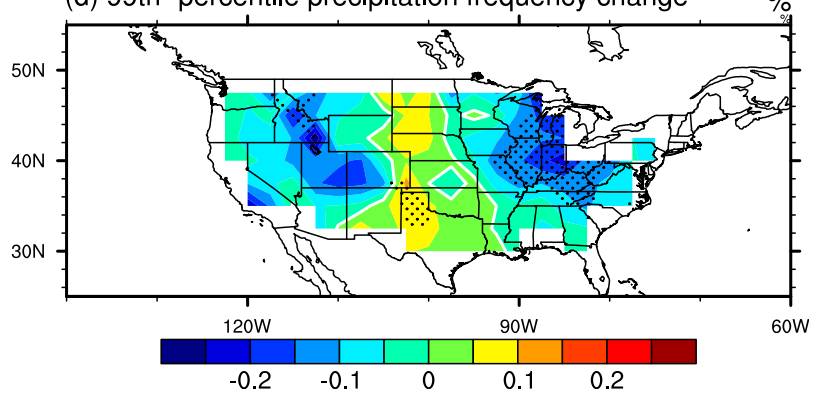

FIG. 16. Projected ECApp-related extreme events frequency change based on CMIP5 28-model equally weighted ensemble mean ECApp change (between 1980-99 and 2079-98) and the point-by-point regression coefficients between observed ECApp and extreme events: (a) CMIP5 28-model ensemble mean change of ECApp, (b) projected 99th percentile extreme cold event frequency change, (c) 99th percentile high wind frequency change (the region where the surface pressure has consistently been below $850 \mathrm{hPa}$ has been masked out), and (d) 99th percentile extreme precipitation frequency change. The dotted areas in (a) indicate regions where ECApp changes are significant at the $5 \%$ level. The dotted areas in (b)-(d) indicate regions where both the ECApp change and the regression coefficient are significant at the $5 \%$ level.

average of the ECApp time series of these three leading SVD modes and call it "the first common mode," whose high and low composites contain the exact same 10 years as the previously defined 10 high- and low-ECApp years. Correlating the time series of the first common mode with the 500-hPa geopotential height and SST, we find that it is highly related with the negative phase of the PNA pattern and ENSO, but not significantly related to the NAO. However, noticeable differences can be found between the composites based on the mapaveraged storm track and those based on the PNA (and ENSO) index. Generally speaking, the impacts of the PNA pattern and ENSO on extreme cold and high wind frequencies are weaker than the impacts of storm-track variations over most of the United States. Our results indicate that while a portion of the storm-track variations could be due to external forcing by ENSO, part of the storm-track variations, and hence their impacts on extreme events, are likely due to internal climate variability that is unrelated to ENSO and the PNA pattern.

Apart from the first common mode, we also find a second common mode, whose composite difference patterns on extreme temperature and the correlation map with the 500-hPa geopotential height resemble, to a certain extent, the 2013/14 winter extreme dipole structure (Hartmann 2015). However, the correlations are weak and not statistically significant, suggesting that the second common mode is only weakly related to the NPM.

Finally, an attempt is made to estimate the potential impact of projected storm-track change under global warming on the occurrence of extreme events. This is done by multiplying the point-by-point regression coefficient between seasonal storm track and extreme event frequency based on observation with the projected future change of storm track found in CMIP5 simulations. Given that CMIP5 models project a significant decrease in cyclone activity in winter (e.g., Chang 2013), the results show up to $30 \%$ reduction in the 99 th percentile extreme cold frequency, $20 \%$ reduction for the 99th percentile high wind frequency, and $15 \%$ reduction for the 99th percentile extreme precipitation. Our regressed reduction in extreme events will reinforce the direct impact of warming over the United States but partly counteract the increase of precipitation under global warming.

The regression technique employed here is probably overly simplistic. Nevertheless, our results indicate extensive regions with potentially significant changes. Given the importance of these impacts, it is necessary to 
further investigate the dynamics behind cyclone activity and extreme weather events, so that more accurate predictions can be made on the impact of cyclone changes on extreme events. It is also important to examine whether state-of-the-art global climate models (GCMs) can accurately simulate the close relations between cyclone and extreme events variability. While one may expect GCMs to be able to simulate these relationships, a recent study (Chang et al. 2016) suggests that simulations using the Community Earth System Model (CESM) systematically underestimate the close relationships between storm-track and cloud variations and maximum temperature over the continental United States, so it is not at all clear that GCMs can accurately capture the impacts of storm-track variations on all of the important weather elements.

Acknowledgments. The authors thank Albert Yau for assisting in processing some of the CMIP5 model data, and three anonymous reviewers for comments that help to clarify the discussions. The authors are supported by DOE Grant DE-SC0014050 and NASA Grant NNX16AG32G.

\section{REFERENCES}

Abatan, A. A., B. J. Abiodun, K. A. Lawal, and W. J. Gutowski, 2016: Trends in extreme temperature over Nigeria from percentile-based threshold indices. Int. J. Climatol., 36, 25272540, doi:10.1002/joc. 4510 .

Alexander, L. V., S. F. B. Tett, and T. Jonsson, 2005: Recent observed changes in severe storms over the United Kingdom and Iceland. Geophys. Res. Lett., 32, L13704, doi:10.1029/ 2005GL022371.

Angel, J. R., and S. Isard, 1998: The frequency and intensity of Great Lake cyclones. J. Climate, 11, 61-71, doi:10.1175/ 1520-0442(1998)011<0061:TFAIOG > 2.0.CO;2.

Ashley, W. S., and A. W. Black, 2008: Fatalities associated with nonconvective high-wind events in the United States. J. Appl. Meteor. Climatol., 47, 717-725, doi:10.1175/ 2007JAMC1689.1.

Barnston, A. G., and R. E. Livezey, 1987: Classification, seasonality and persistence of low-frequency atmospheric circulation patterns. Mon. Wea. Rev., 115, 1083-1126, doi:10.1175/ 1520-0493(1987)115<1083:CSAPOL>2.0.CO;2.

Bengtsson, L., K. I. Hodges, and E. Roeckner, 2006: Storm tracks and climate change. J. Climate, 19, 3518-3543, doi:10.1175/ JCLI3815.1.

,-- , and N. Keenlyside, 2009: Will extratropical storms intensify in a warmer climate? J. Climate, 22, 2276-2301, doi:10.1175/2008JCLI2678.1.

Blackmon, M. L., J. M. Wallace, N.-C. Lau, and S. L. Mullen, 1977: An observational study of the Northern Hemisphere wintertime circulation. J. Atmos. Sci., 34, 1040-1053, doi:10.1175/ 1520-0469(1977)034<1040:AOSOTN>2.0.CO;2.

_ - Y.-H. Lee, and H.-H. Hsu, 1984a: Time variation of 500-mb height fluctuations with long, intermediate and short time scales as deduced from lag-correlation statistics. J. Atmos.
Sci., 41, 981-991, doi:10.1175/1520-0469(1984)041<0981: TVOMHF $>2.0$.CO;2.

$\ldots,-$, and J. M. Wallace, 1984b: Horizontal structure of 500-mb height fluctuations with long, intermediate and short time scales. J. Atmos. Sci., 41, 961-979, doi:10.1175/ 1520-0469(1984)041<0961:HSOMHF>2.0.CO;2.

Booth, J. F., S. Wang, and L. Polvani, 2013: Midlatitude storms in a moister world: Lessons from idealized baroclinic life cycle experiments. Climate Dyn., 41, 787-802, doi:10.1007/ s00382-012-1472-3.

Bosart, L. F., 1981: The Presidents' Day Snowstorm of 1819 February 1979: A subsynoptic-scale event. Mon. Wea. Rev., 109, 1542-1566, doi:10.1175/1520-0493(1981)109<1542: TPDSOF $>2.0 . \mathrm{CO} ; 2$.

Bretherton, C., C. Smith, and J. Wallace, 1992: An intercomparison of methods to find coupled patterns in climate data. J. Climate, 5, 541-560, doi:10.1175/1520-0442(1992)005<0541: $\mathrm{AIOMFF}>2.0 . \mathrm{CO} ; 2$.

Caesar, J., L. Alexander, and R. Vose, 2006: Large-scale changes in observed daily maximum and minimum temperatures: Creation and analysis of a new gridded data set. J. Geophys. Res., 111, D05101, doi:10.1029/2005JD006280.

Cai, M., and M. Mak, 1990: Symbiotic relation between planetary and synoptic-scale waves. J. Atmos. Sci., 47, 2953-2968, doi:10.1175/1520-0469(1990)047<2953:SRBPAS > 2.0.CO;2.

Cardone, V. J., R. E. Jensen, D. T. Resio, V. R. Swail, and A. T. Cox, 1996: Evaluation of contemporary ocean wave models in rare extreme events: The "Halloween storm" of October 1991 and the "storm of the century" of March 1993. J. Atmos. Oceanic Technol., 13, 198-230, doi:10.1175/1520-0426(1996)013<0198: EOCOWM $>2.0 . \mathrm{CO} ; 2$.

Chang, E. K. M., 2013: CMIP5 projection of significant reduction in extratropical cyclone activity over North America. J. Climate, 26, 9903-9922, doi:10.1175/JCLI-D-13-00209.1.

— Y. Guo, and X. Xia, 2012: CMIP5 multimodel ensemble projection of storm track change under global warming. J. Geophys. Res., 117, D23118, doi:10.1029/2012JD018578.

_ C.-G. Ma, C. Zheng, and A. M. W. Yau, 2016: Observed and projected decrease in Northern Hemisphere extratropical cyclone activity in summer and its impacts on maximum temperature. Geophys. Res. Lett., 43, 2200-2208, doi:10.1002/ 2016GL068172.

Chen, M., and Coauthors, 2008: Assessing objective techniques for gauge-based analyses of global daily precipitation. J. Geophys. Res., 113, D04110, doi:10.1029/2007JD009132.

Chou, C., and J. Neelin, 2004: Mechanisms of global warming impacts on regional tropical precipitation. J. Climate, 17, 2688-2701, doi:10.1175/1520-0442(2004)017<2688:MOGWIO>2.0.CO;2.

Collins, M., and Coauthors, 2013: Long-term climate change: Projections, commitments and irreversibility. Climate Change 2013: The Physical Science Basis, T. F. Stocker et al., Eds., Cambridge University Press, 1029-1136.

Dickson, R. R., and J. Namias, 1976: North American influences on the circulation and climate of the North Atlantic sector. Mon. Wea. Rev., 104, 1255-1265, doi:10.1175/ 1520-0493(1976)104<1255:NAIOTC > 2.0.CO;2.

Eichler, T., and W. Higgins, 2006: Climatology and ENSO-related variability of North American extratropical cyclone activity. J. Climate, 19, 2076-2093, doi:10.1175/JCLI3725.1.

Emori, S., and S. J. Brown, 2005: Dynamic and thermodynamic changes in mean and extreme precipitation under changed climate. Geophys. Res. Lett., 32, L17706, doi:10.1029/ 2005GL023272. 
Feser, F., M. Barcikowska, O. Krueger, F. Schenk, R. Weisse, and L. Xia, 2015: Storminess over the North Atlantic and northwestern Europe-A review. Quart. J. Roy. Meteor. Soc., 141, 350-382, doi:10.1002/qj.2364.

Francis, J. A., and S. J. Vavrus, 2012: Evidence linking Arctic amplification to extreme weather in mid-latitudes. Geophys Res. Lett., 39, L06801, doi:10.1029/2012GL051000.

Frierson, D. M. W., 2006: Robust increases in midlatitude static stability in simulations of global warming. Geophys. Res. Lett., 33, L24816, doi:10.1029/2006GL027504.

Grise, K. M., S. W. Son, and J. R. Gyakum, 2013: Intraseasonal and interannual variability in North American storm tracks and its relationship to equatorial Pacific variability. Mon. Wea. Rev., 141, 3610-3625, doi:10.1175/MWR-D-12-00322.1.

Hartmann, D. L., 2015: Pacific sea surface temperature and the winter of 2014. Geophys. Res. Lett., 42, 1894-1902, doi:10.1002/2015GL063083.

Harvey, B. J., L. C. Shaffrey, T. J. Woollings, G. Zappa, and K. I. Hodges, 2012: How large are projected 21st century storm track changes? Geophys. Res. Lett., 39, L18707, doi:10.1029/ 2012GL052873.

Held, I., and B. Soden, 2006: Robust responses of the hydrological cycle to global warming. J. Climate, 19, 5686-5699, doi:10.1175/JCLI3990.1.

Higgins, R. W., A. Leetmaa, and V. E. Kousky, 2002: Relationships between climate variability and winter temperature extremes in the United States. J. Climate, 15, 1555-1572, doi:10.1175/ 1520-0442(2002)015<1555:RBCVAW $>2.0 . \mathrm{CO} ; 2$.

Hirsch, M. E., A. T. DeGaetano, and S. J. Colucci, 2001: An East Coast winter storm climatology. J. Climate, 14, 882-899, doi:10.1175/1520-0442(2001)014<0882:AECWSC >2.0.CO;2.

Hodges, K. I., 1999: Adaptive constraints for feature tracking. Mon. Wea. Rev., 127, 1362-1373, doi:10.1175/1520-0493(1999)127<1362: ACFFT $>2.0 . \mathrm{CO} ; 2$.

Holland, M. M., and C. M. Bitz, 2003: Polar amplification of climate change in coupled models. Climate Dyn., 21, 221-232, doi:10.1007/s00382-003-0332-6.

Horel, J. D., and J. M. Wallace, 1981: Planetary-scale atmospheric phenomena associated with the Southern Oscillation. Mon. Wea. Rev., 109, 813-829, doi:10.1175/1520-0493(1981)109<0813: PSAPAW $>2.0 . \mathrm{CO} ; 2$.

Hoskins, B. J., and K. I. Hodges, 2002: New perspectives on the Northern Hemisphere winter storm tracks. J. Atmos. Sci., 59, 1041-1061, doi:10.1175/1520-0469(2002)059<1041 $\mathrm{NPOTNH}>2.0 . \mathrm{CO} ; 2$.

Jones, P. W., 1999: First- and second-order conservative remapping schemes for grids in spherical coordinates. Mon. Wea. Rev., 127, 2204-2210, doi:10.1175/1520-0493(1999)127<2204: FASOCR $>2.0 . \mathrm{CO} ; 2$.

Karremann, M. K., J. G. Pinto, M. Reyers, and M. Klawa, 2014: Return periods of losses associated with European windstorm series in a changing climate. Environ. Res. Lett., 9, 124016, doi:10.1088/1748-9326/9/12/124016.

Klawa, M., and U. Ulbrich, 2003: A model for the estimation of storm losses and the identification of severe winter storms in Germany. Nat. Hazards Earth Syst. Sci., 3, 725-732, doi:10.5194/nhess-3-725-2003.

Kunkel, K. E., and J. R. Angel, 1999: Relationship of ENSO to snowfall and related cyclone activity in the contiguous United States. J. Geophys. Res., 104, 19425-19434, doi:10.1029/ 1999JD900010.

- D. R. Easterling, D. A. R. Kristovich, B. Gleason, L. Stoecker, and R. Smith, 2012: Meteorological causes of the secular variations in observed extreme precipitation events for the conterminous United States. J. Hydrometeor., 13, 11311141, doi:10.1175/JHM-D-11-0108.1.

Kutzbach, J., J. Williams, and S. Vavrus, 2005: Simulated 21st century changes in regional water balance of the Great Lakes region and links to changes in global temperature and poleward moisture transport. Geophys. Res. Lett., 32, L17707, doi:10.1029/2005GL023506.

Lau, N.-C., 1978: On the three-dimensional structure of the observed transient eddy statistics of the Northern Hemisphere wintertime circulation. J. Atmos. Sci., 35, 1900-1923, doi:10.1175/ 1520-0469(1978)035<1900:OTTDSO > 2.0.CO;2.

- 1988: Variability of the observed midlatitude storm tracks in relation to low-frequency changes in the circulation pattern. J. Atmos. Sci. 45, 2718-2743, doi:10.1175/1520-0469(1988)045<2718: VOTOMS $>2.0 . \mathrm{CO} ; 2$.

Leathers, D. J., B. Yarnal, and M. A. Palecki, 1991: The Pacific/North American teleconnection pattern and United States climate. Part I: Regional temperature and precipitation associations. J. Climate, 4, 517-528, doi:10.1175/1520-0442(1991)004<0517: TPATPA $>2.0 . \mathrm{CO} ; 2$

Lim, E.-P., and I. Simmonds, 2009: Effects of tropospheric temperature change on zonal mean circulation and $\mathrm{SH}$ winter extratropical cyclones. Climate Dyn., 33, 19-32, doi:10.1007/ s00382-008-0444-0.

Lu, J., and M. Cai, 2009: Seasonality of polar surface warming amplification in climate simulations. Geophys. Res. Lett., 36, L16704, doi:10.1029/2009GL040133.

Meehl, G., and Coauthors, 2007: Global climate projections. Climate Change 2007: The Physical Science Basis. S. Solomon et al., Eds., Cambridge University Press, 747-845.

Namias, J., 1978: Multiple causes of the North American abnormal winter of 1976-77. Mon. Wea. Rev., 106, 279-295, doi:10.1175/ 1520-0493(1978)106<0279:MCOTNA>2.0.CO;2.

Neu, U., and Coauthors, 2013: IMILAST: A community effort to intercompare extratropical cyclone detection and tracking algorithms. Bull. Amer. Meteor. Soc., 94, 529-547, doi:10.1175/ BAMS-D-11-00154.1.

Ning, L., and R. S. Bradley, 2015: Winter climate extremes over the northeastern United States and southeastern Canada and teleconnections with large-scale modes of climate variability. J. Climate, 28, 2475-2493, doi:10.1175/JCLI-D-13-00750.1.

Noel, J., and D. Changnon, 1998: A pilot study examining U.S. winter cyclone frequency patterns associated with three ENSO parameters. J. Climate, 11, 2152-2159, doi:10.1175/1520-0442-11.8.2152.

Petterssen, S., 1956: Weather Analysis and Forecasting. Vol. 1, McGraw-Hill, 428 pp.

Pfahl, S., and H. Wernli, 2012: Quantifying the relevance of cyclones for precipitation extremes. J. Climate, 25, 6770-6780, doi:10.1175/JCLI-D-11-00705.1.

Philander, S. G. H., 1985: El Niño and La Niña. J. Atmos. Sci., 42, 2652-2662, doi:10.1175/1520-0469(1985)042<2652: ENALN $>2.0 . \mathrm{CO} ; 2$.

_ 1990: El Niño, La Niña and the Southern Oscillation. Academic Press, 293 pp.

Raible, C. C., P. M. Della-Marta, C. Schwierz, H. Wernli, and R. Blender, 2008: Northern Hemisphere extratropical cyclones: A comparison of detection and tracking methods and different reanalyses. Mon. Wea. Rev., 136, 880-897, doi:10.1175/2007MWR2143.1.

Rayner, N. A., D. E. Parker, E. B. Horton, C. K. Folland, L. V. Alexander, D. P. Rowell, E. C. Kent and A. Kaplan, 2003: Global analyses of sea surface temperature, sea ice, and night 
marine air temperature since the late nineteenth century. J. Geophys. Res., 108, 4407, doi:10.1029/2002JD002670.

Seager, R., N. Naik, and G. Vecchi, 2010: Thermodynamic and dynamic mechanisms for large-scale changes in the hydrological cycle in response to global warming. J. Climate, 23, 4651-4668, doi:10.1175/2010JCLI3655.1.

Sen Roy, S., and R. C. Balling, 2004: Trends in extreme daily precipitation indices in India. Int. J. Climatol, 24, 457-466, doi:10.1002/joc.995.

Wallace, J. M., and D. S. Gutzler, 1981: Teleconnections in the geopotential height field during the Northern Hemisphere winter. Mon. Wea. Rev., 109, 784-812, doi:10.1175/ 1520-0493(1981)109<0784:TITGHF>2.0.CO;2.
_ G.-H. Lim, and M. L. Blackmon, 1988: Relationship between cyclone tracks, anticyclone tracks, and baroclinic waveguides. J. Atmos. Sci., 45, 439-462, doi:10.1175/1520-0469(1988) 045<0439:RBCTAT $>2.0$. CO;2.

Xie, P., M. Chen, S. Yang, A. Yatagai, T. Hayasaka, Y. Fukushima, and C. Liu, 2007: A gauge-based analysis of daily precipitation over East Asia. J. Hydrometeor., 8, 607-626, doi:10.1175/ JHM583.1.

Zhang, F., C. Snyder, and R. Rotunno, 2002: Mesoscale predictability of the "surprise" snowstorm of 24-25 January 2000. Mon. Wea. Rev., 130, 1617-1632, doi:10.1175/1520-0493(2002)130<1617: MPOTSS $>2.0 . \mathrm{CO} ; 2$. 